\title{
Open and partially closed models of the solar wind interaction with outer planet magnetospheres: the case of Saturn
}

\author{
Elena S. Belenkaya ${ }^{1}$, Stanley W. H. Cowley ${ }^{2}$, Igor I. Alexeev ${ }^{1}$, Vladimir V. Kalegaev ${ }^{1}$, Ivan A. Pensionerov ${ }^{1}$, \\ Marina S. Blokhina ${ }^{1}$, and David A. Parunakian ${ }^{1}$ \\ ${ }^{1}$ Federal State Budget Educational Institution of Higher Education M.V. Lomonosov Moscow State University, \\ Skobeltsyn Institute of Nuclear Physics (SINP MSU), 1(2), Leninskie Gory, GSP-1, Moscow 119991, Russian Federation \\ ${ }^{2}$ Department of Physics and Astronomy, University of Leicester, Leicester LE1 7RH, UK \\ Correspondence to: Elena S. Belenkaya (elena@dec1.sinp.msu.ru)
}

Received: 26 April 2017 - Revised: 27 October 2017 - Accepted: 1 November 2017 - Published: 6 December 2017

\begin{abstract}
A wide variety of interactions take place between the magnetized solar wind plasma outflow from the Sun and celestial bodies within the solar system. Magnetized planets form magnetospheres in the solar wind, with the planetary field creating an obstacle in the flow. The reconnection efficiency of the solar-wind-magnetized planet interaction depends on the conditions in the magnetized plasma flow passing the planet. When the reconnection efficiency is very low, the interplanetary magnetic field (IMF) does not penetrate the magnetosphere, a condition that has been widely discussed in the recent literature for the case of Saturn. In the present paper, we study this issue for Saturn using Cassini magnetometer data, images of Saturn's ultraviolet aurora obtained by the HST, and the paraboloid model of Saturn's magnetospheric magnetic field. Two models are considered: first, an open model in which the IMF penetrates the magnetosphere, and second, a partially closed model in which field lines from the ionosphere go to the distant tail and interact with the solar wind at its end. We conclude that the open model is preferable, which is more obvious for southward IMF. For northward IMF, the model calculations do not allow us to reach definite conclusions. However, analysis of the observations available in the literature provides evidence in favor of the open model in this case too. The difference in magnetospheric structure for these two IMF orientations is due to the fact that the reconnection topology and location depend on the relative orientation of the IMF vector and the planetary dipole magnetic moment. When these vectors are parallel, two-dimensional reconnection occurs at the low-latitude neutral line. When they are antiparallel, three-dimensional reconnection takes place in the cusp regions. Different mag-
\end{abstract}

netospheric topologies determine different mapping of the open-closed boundary in the ionosphere, which can be considered as a proxy for the poleward edge of the auroral oval.

Keywords. Magnetospheric physics (solar windmagnetosphere interactions; planetary magnetospheres; auroral phenomena)

\section{Introduction}

The nature of the interaction of the solar wind with planetary magnetospheres in interplanetary space is a key question in heliospheric physics. This interaction has a specific behavior for each planet, depending on the parameters of the solar wind in the planetary environment and on the planetary properties. For Mercury, the principal factors involved are its small distance from the Sun, which determines the solar wind properties together with the small planetary magnetic field and the strong interplanetary magnetic field (IMF) of which the radial component is dominant. For Venus and Mars, which are unmagnetized (except for small-scale fields in the southern hemisphere in the case of Mars), perturbations of the solar wind and IMF resulting from its interaction with the planet's conducting ionosphere lead to the formation of an induced magnetosphere. For the well-studied case of the Earth, the magnetized solar wind is the main source of terrestrial magnetospheric dynamics. For the outer planets, their strong fields, major internal sources of plasma (for example moons embedded within the magnetospheres of Jupiter and Saturn), and fast spin can also affect the interac- 
tion with the solar wind (e.g., Khurana et al., 2004; Krupp et al., 2004; Belenkaya, 2004, 2009; Connerney et al., 2017).

The question of how auroras are generated at each magnetized planet has been widely discussed in the literature (e.g., Saur et al., 2003; Hultqvist, 2008; Clarke et al., 2004, 2009; Clarke, 2012; Mauk and Bagenal, 2012) and may generally be expected to be closely connected with the type of solar wind-magnetosphere interaction present. The main oval emission at Jupiter is an exception, as it is thought to be generated by the braking of plasma rotation in the equatorial magnetosphere due to the radial transport of plasma from the moon Io (Hill, 2001; Cowley and Bunce, 2001), though higher-latitude auroras may be linked to the solar wind interaction. As the volume of relevant data and theoretical interpretation grows, it appears that there is a specific source of aurora for each magnetized planet. For the Earth, the auroras are powered principally by the flow of the magnetized solar wind, which generates strong field-aligned currents flowing between the ionosphere and magnetosphere that are connected with the auroral emissions (e.g., Dungey, 1961; Alfvén, 1967; Cowley, 1981; Cowley and Hughes, 1983; Cowley and Lockwood, 1992, 1996; Feldstein et al., 2014; Feldstein, 2016). For Jupiter, the auroras are powered mainly by the energy of planetary rotation (Hill, 2001; Cowley et al., 2003a), though the solar wind effects are also observed in the Jovian magnetosphere (e.g., Cowley and Bunce, 2003a; Belenkaya, 2004) and in the open ionospheric field line region, which occupies part of the area inside the main oval emission (e.g., Cowley et al., 2003b). Grodent et al. (2003), Pallier and Prangé (2001), and Vogt et al. (2011) suggested that the so-called auroral "swirl" region coincides with the region of open ionospheric flux, which observations show to occupy approximately one-third of the area inside Jupiter's main oval. This interpretation was supported by the calculations of Belenkaya et al. (2006a) using the paraboloid model of Jupiter's magnetospheric magnetic field (see Alexeev and Belenkaya, 2005, and references therein) with an interplanetary magnetic field (IMF) value $\sim 0.5 \mathrm{nT}$, which is characteristic of Jupiter's solar wind environment. The breakdown of Jupiter's magnetospheric plasma rotation in the equatorial magnetosphere creates strong upward field-aligned currents flowing from the ionosphere (Hill, 2001; Cowley et al., 2003a; Cowley and Bunce, 2003a) to the inner region of Jupiter's magnetodisc located at the Alfvén radius (Alexeev and Belenkaya, 2005; Belenkaya and Khodachenko, 2012).

For Saturn, the role of internal processes is also important, particularly the outflow of gas from the moon Enceladus, but the influence of the solar wind and IMF is highly significant too. Calculations made by Cowley and Bunce (2003b) showed that the upward field-aligned currents associated with the breakdown of rigid corotation in the equatorial magnetosphere as measured by Voyager (Richardson, 1986; Richardson and Sittler Jr., 1990) and more recently by Cassini (e.g., Müller et al., 2010; Wilson et al., 2017) do not produce the observed ultraviolet (UV) aurora in Saturn's main oval, unlike the case of Jupiter. Instead, Saturn's auroral oval is most probably related to the effects of the solar wind and IMF, as at Earth. Magnetospheric structure depends on the type of reconnection (2-D or 3-D), which in turn is determined by the IMF component along the planetary dipole magnetic moment. Cowley et al. (2003a, b, 2004a, 2008), Cowley and Bunce (2003b), and Bunce et al. (2008) suggested that Saturn's oval is placed close to the ionospheric boundary of open magnetic flux where the plasma angular velocity is expected to fall sharply with increasing latitude. Calculations using the paraboloid model of Saturn's magnetospheric magnetic field (Alexeev et al., 2006) support this suggestion (e.g., Belenkaya et al., 2011, and references therein). Based on Cassini and HST data, Cowley et al. (2005) discussed the dependence of UV auroral and Saturn kilometric radiation emissions on the solar wind dynamic pressure and explained it in terms of pressure-induced enhanced tail reconnection in a rotation-dominated magnetosphere. The authors emphasized that the influence of the north-south IMF component on Saturn's magnetosphere, which changes rapidly on timescales of tens of minutes up to several hours, is controlled on the timescale of the solar wind passage along the tail of several days, which is thus hard to distinguish. For this reason, the IMF dependence of the auroral dynamics must be studied by considering the corresponding large response time.

Reconnection on the dayside is influenced by the formation of plasma depletion layers (PDLs) in the magnetosheath immediately upstream of the magnetopause. The prominence of the PDL has been shown to be determined by how the magnetic flux transfer rate caused by reconnection compares with the rate of competing magnetic flux advection by the solar wind (Anderson et al., 1997). As PDLs have a lower plasma $\beta$ than the magnetosheath near the bow shock, they promote higher magnetic reconnection rates (Scurry et al., 1994), which in turn act to diminish the PDL. Various spacecraft have succeeded in detecting PDL signatures at various different planets, as we now briefly discuss. At Mercury's magnetopause, the observed reconnection rate is substantially higher than at Earth (Slavin et al., 2009; DiBraccio et al., 2013), yet it is still insufficient to transfer and distribute the entire magnetic flux pileup around the magnetosphere quickly enough. Consequently, the pileup still generates a persistent large-scale PDL, which in turn leads to further growth of the average magnetopause reconnection rate (Gershman et al., 2013). Examination of Venus Express magnetometer data has also led to the identification of a clear boundary at the top of the magnetic barrier between the inner and outer magnetosheath regions characterized by their significantly differing levels of wave activity and magnetic field draping (Zhang et al., 2008). Phan et al. (1994) found that at Earth a plasma depletion layer arises for strong northward IMF and becomes disturbed for southward IMF. Magnetic pileup and the associated plasma density decrease upstream of Mars first reported from MGS spacecraft measurements by 
Vignes et al. (2000) have been shown to be permanent structures, although the location of the nightside pileup boundary appears to be highly dynamic. It has been suggested by Øieroset et al. (2004) that the induced Martian magnetospheric obstacle may be created by the slowdown of plasma flow due to the mass loading from atmospheric neutrals and the subsequent stagnation of the magnetic field carried by the plasma. Finally, in contrast to its terrestrial counterpart, the PDL at Jupiter's magnetopause has been found not to respond significantly to variations in the magnetic shear across the magnetopause. The magnetic flux transport rate due to reconnection in this case appears to be lower than the rate of magnetic flux advection due to the solar wind flow. This may imply that conditions for magnetopause reconnection are less favorable at Saturn compared to those at the Earth (Masters et al., 2014).

No clear understanding of the interaction processes between the magnetized solar wind and Saturn's magnetosphere has been achieved to date. Scurry and Russell (1991) suggested that the reconnection efficiency near Saturn is low due to the usual high magnetosonic Mach number of the solar wind flow at these distances, though this conclusion has been disputed by Grocott et al. (2009). For related reasons, Masters et al. (2014) have expressed doubt about the importance of reconnection at Saturn's magnetopause. They noted that despite reconnection signatures being observed in Saturn's magnetosphere (e.g., McAndrews et al., 2008; Radioti et al., 2011, 2013; Badman et al., 2013), the reconnection efficiency at Saturn may be much lower than at Earth due to the different solar wind conditions at these planets. Investigation of this subject is also significant for other magnetic planets and exoplanets located in the flow of magnetized plasma. In this paper we consider two modes of solar wind-magnetosphere interaction at Saturn, namely with zero and with nonzero permeability of the magnetopause to the IMF.

\section{Comparison of open and partially closed Saturn magnetospheric models}

The open paraboloid model of Saturn's magnetospheric magnetic field was constructed and described by Alexeev et al. (2006) and has been used by Belenkaya et al. (2006b, 2007, $2008,2010,2011,2013,2014)$ in a number of subsequent investigations. The sources of magnetic field in this model are (i) the planetary magnetic field, (ii) the tail current system, (iii) the ring current, and (iv) the magnetopause shielding currents. The IMF is also allowed to partially penetrate the magnetosphere, with a penetration coefficient $k$ (the reconnection efficiency); i.e., the penetrating field is taken to be $k$ times the IMF vector. The value of $k$ is taken to be 0.2 as in the terrestrial magnetosphere, though this value is not known with certainty. An analytic solution for the value of the penetrating part of the IMF into the terrestrial magnetosphere was given by Alexeev (1986). Calculations using the Kronian paraboloid model show that the ionospheric open field line area is almost insensitive to variations in $k$ (excluding the case $k=0$ ), especially for northward IMF (see Sect. 5). The Alexeev et al. (2006) model was used in papers by Belenkaya et al. (2006b, 2007, 2008, 2010, 2011, 2013, 2014) to compare the high-latitude edge of Saturn's auroral oval with the model open-closed ionospheric field line boundary, the results of which supported the idea that these boundaries are located rather close to each other (Cowley and Bunce, 2003a; Cowley et al., 2004a; Bunce et al., 2008). The IMF data used in these studies were obtained from Cassini magnetometer data when available, while the auroral boundaries were determined from Hubble Space Telescope (HST) UV images. Cowley et al. (2004a) suggested that strong upward field-aligned currents associated with the auroral emissions are generated due to the azimuthal velocity shear between closed and open field lines. Closed field lines corotate with modest lag from rigid corotation, while on the open field lines corotation partially breaks dawn (with $\sim 30 \%$ of rigid corotation; Stallard et al., 2004; Hunt et al., 2015), as they are dragged tailward by the solar wind. The strong upward field-aligned currents flowing at the boundary between the two different types of field lines are carried by downwardaccelerated magnetospheric electrons, which excite auroral emissions at ionospheric height in the auroral oval. The detailed correspondence has been investigated using multiinstrument Cassini data by Jinks et al. (2014), who found that the upward field-aligned currents are located just equatorward of the polar cap boundary, with an offset of $\sim 1.5-$ $1.8^{\circ}$ colatitude. The polar cap was determined by Jinks et al. (2014) as follows. "The polar cap boundary can be clearly observed in the step in the upper cutoff of auroral hiss emissions from the plasma wave data, a sudden increase in electron density, an anisotropy of energetic electrons along the magnetic field, and an increase in incidence of higher-energy electrons from the low-energy electron spectrometer measurements as we move equatorward from the pole". In this paper the term "polar cap" is taken to be the area bounded by the auroral oval. Since the strong upward currents associated with the auroral oval are located on closed field lines just equatorward of the open-closed boundary (Jinks et al., 2014; Hunt et al., 2015), this polar cap region will consist almost wholly of open field lines.

However, strong field-aligned currents at the boundary between topologically different field regions could arise not only in the case of an open magnetosphere. If we suppose that Saturn's magnetopause is not permeable to the IMF but that the IMF can interact with the magnetospheric field at the end of the magnetospheric tail, then the field lines mapping to the distant tail can be considered as open, as shown in Fig. 1. The situation in which open field lines arise in a closed magnetosphere was already investigated for the case of the Earth by Alexeev et al. (1998). Figure 1a and b demonstrate the structure of a "partially closed" Saturn magneto- 
(a)

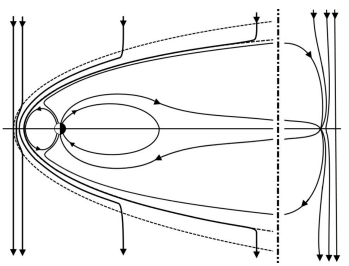

(b)

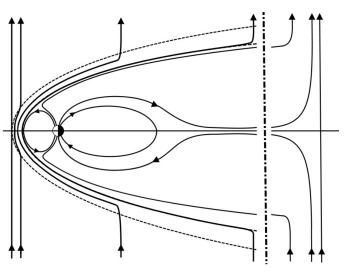

Figure 1. Partially closed magnetospheric model for (a) southward and (b) northward IMF.

sphere for southward and northward IMF, respectively. The magnetopause is surrounded by an outer boundary layer located between the dashed curves, within which the draped IMF lines are compressed. At the end of the tail beyond the dot-dashed line, there is a tail boundary layer perpendicular to the line of the tail, through which the IMF interacts with the magnetospheric field. By analogy with the Earth's closed magnetosphere, due to viscosity the motion on the closed field lines may be anti-sunward at higher latitudes and sunward at lower latitudes. Closed field lines coming to the end of the tail meet the interplanetary lines there approaching the equatorial reconnection region from the north and south after passing the magnetosphere. As a result, lines open through the tail boundary layer may arise. For northward IMF (Fig. 1b) the tail lines can map away from the tail boundary layer to finally become interplanetary field lines, while for southward IMF (Fig. 1a) there is a specific point at which magnetic field lines are gathered in the equatorial tail boundary layer, beyond which the IMF is restored. Due to this kind of tail reconnection, the solar wind potential drop across the magnetosphere can be applied to the separatrix surfaces dividing different topological types of field lines, along which strong field-aligned currents flow that could be associated with auroral oval emissions. The lobe lines in the partially closed model start at the planet and eventually pass into the solar wind. For this reason they can be considered to be open lines. We now try to check which of these two modes of solar wind-magnetosphere interaction occurs at Saturn, open or partially closed as in Fig. 1. To do this we compare the open-closed boundaries calculated for these two modes with the auroral oval location observed in a series of HST images.

\section{Calculations using the paraboloid model}

We have selected several HST UV images as listed in Table 1, eight images for southward IMF and seven images for northward, for which the open-closed boundary in the ionosphere was calculated using the open paraboloid model and published in papers by Belenkaya et al. (2007, 2008, 2010, 2014) (denoted in the table and figures here by B[2007], B[2008], $\mathrm{B}$ [2010], and $\mathrm{B}$ [2014]). The corresponding IMF vectors were determined in each case from Cassini magnetometer data

when the spacecraft was located in the solar wind upstream of the planet. The detailed description of how these IMF vectors were determined is given in the papers cited. From left to right, the columns of Table 1 give the UV image case number employed here, the corresponding date (yearmonth-day), the hemisphere in which the aurora was observed (southern or northern), the image time (UT), the corresponding IMF vector (nT), the magnetospheric state (expanded, compressed, or intermediate) for which the model set of parameters was used, the dipole tilt angle $\Psi$, and the paper in which paraboloid model calculations were presented together with the image identifier (e.g., "image f" or "visit H4"). The IMF vectors are given in Kronocentric Solar Magnetospheric (KSM) coordinates $\left(B_{x}, B_{y}, B_{z}\right)$, where $X$ points from the planet's center towards the Sun, the $X-Z$ plane contains Saturn's spin/magnetic axis, and $Y$ completes the right-hand triad. The dipole tilt angle, $\Psi$, is measured between the planetary magnetic moment axis and the $Z$ axis in the KSM coordinate system.

The ionospheric open-closed field line boundaries calculated using the paraboloid model for both the open and partially closed magnetosphere models are shown in Fig. 2 for the case of southward IMF and in Fig. 3 for northward IMF. The sets of model parameters employed in these calculations were determined for each case in the corresponding papers using compressed, intermediate, and expanded magnetospheric states depending on the solar wind dynamic pressure and according to the classification given in Belenkaya et al. (2008). For southward IMF in Fig. 2, the open flux area for the partially closed magnetosphere bounded by the orange curve is larger, mainly in the dawn-dusk direction, than for the open magnetosphere case bounded by the red curve. The relative shift is dawnward (duskward) for negative (positive) IMF $B_{y}$ in the northern hemisphere and vice versa in the southern hemisphere. The difference between the two models is more strongly expressed for southward IMF when the ratio $\left|B_{z}\right| /\left|B_{x}\right|>1$. This condition is realized for cases 1,5 , 6 , and 8 from Table 1 (see Fig. 2). On the other hand, for the northward IMF cases in Fig. 3 the boundaries for both models are almost the same, except for a small region in the noon sector where the open magnetosphere model gives a small extension to the open field region. Comparing these boundaries with the observed UV oval emissions in both figures, it appears that the open magnetosphere model, which allows for IMF penetration, better describes the area inside the auroral oval for southward IMF (Fig. 2), while for northward IMF both models give rather similar results (Fig. 3).

It should be mentioned that the tail length $L_{\text {tail }}$ for the partially closed Kronian magnetosphere is much shorter than for the open tail, as in the first case the solar wind does not drag the magnetospheric field lines in the anti-sunward direction. However, some kind of viscous effect exists, which is not so effective as the solar wind-IMF effect. For the open magnetosphere with $k \neq 0$, the time taken by the solar wind to traverse the length of the tail is $t_{\text {tail }}=L_{\text {tail }} / V_{\mathrm{sw}}$, where $V_{\mathrm{sw}}$ 
Table 1. The case numbers of the UV images considered in this paper are listed together with the date, the hemisphere in which the aurora was observed, UT, KSM IMF components, magnetospheric state corresponding to the set of model parameters employed, tilt angle $\Psi$, and the reference and image identifier.

\begin{tabular}{|c|c|c|c|c|c|c|}
\hline $\begin{array}{l}\text { Case } \\
\text { number }\end{array}$ & $\begin{array}{l}\text { Date } \\
\text { (year-month-day), } \\
\text { hemisphere }\end{array}$ & $\begin{array}{r}\text { UT } \\
(\mathrm{h}: \min : \mathrm{s})\end{array}$ & $\begin{array}{r}\text { KSM IMF } \\
\text { components } \\
(\mathrm{nT})\end{array}$ & $\begin{array}{l}\text { Set of } \\
\text { parameters }\end{array}$ & $\begin{array}{l}\Psi \\
\left(^{\circ}\right)\end{array}$ & $\begin{array}{l}\text { Reference } \\
\text { and image } \\
\text { identifier }\end{array}$ \\
\hline 1 & $\begin{array}{l}\text { 2004-01-18 } \\
\text { southern }\end{array}$ & 04:40:14 & $0.0 ;-0.4 ;-0.4$ & expanded & 24.9 & $\begin{array}{l}\mathrm{B}[2008] \\
\text { image f }\end{array}$ \\
\hline 2 & $\begin{array}{l}\text { 2008-02-12 } \\
\text { southern }\end{array}$ & $21: 47: 38$ & $0.2 ;-0.8 ;-0.2$ & compressed & 6.5 & $\begin{array}{l}\mathrm{B}[2010], \\
\text { image A }\end{array}$ \\
\hline 3 & $\begin{array}{l}\text { 2008-02-13 } \\
\text { southern }\end{array}$ & $00: 47: 44$ & $0.3 ;-0.8 ;-0.1$ & compressed & 6.5 & $\begin{array}{l}\text { B[2010], } \\
\text { image B }\end{array}$ \\
\hline 4 & $\begin{array}{l}\text { 2011-04-07 } \\
\text { northern }\end{array}$ & $06: 26: 11$ & $-0.2 ;-0.6 ;-0.2$ & compressed & -10.8 & $\begin{array}{l}\mathrm{B}[2014] \text {, } \\
\text { visit } \mathrm{H} 4\end{array}$ \\
\hline 5 & $\begin{array}{l}\text { 2012-04-02 } \\
\text { northern }\end{array}$ & $10: 48: 56$ & $-0.0 ;-0.3 ;-0.5$ & intermediate & -15.5 & $\begin{array}{l}\mathrm{B}[2014], \\
\text { visit I6 }\end{array}$ \\
\hline 6 & $\begin{array}{l}\text { 2012-04-03 } \\
\text { northern }\end{array}$ & $10: 45: 49$ & $-0.1 ;-0.4 ;-0.4$ & intermediate & -15.5 & $\begin{array}{l}\text { B[2014], } \\
\text { visit I7 }\end{array}$ \\
\hline 7 & $\begin{array}{l}\text { 2012-04-03 } \\
\text { northern }\end{array}$ & $13: 54: 13$ & $-0.3 ;-0.3 ;-0.2$ & intermediate & -15.5 & $\begin{array}{l}\mathrm{B}[2014], \\
\text { visit I8 }\end{array}$ \\
\hline 8 & $\begin{array}{l}\text { 2004-01-26 } \\
\text { southern }\end{array}$ & $19: 02: 32$ & $0.5 ;-2.0 ;-1.4$ & compressed & 24.8 & $\begin{array}{l}\mathrm{B} \text { [2007], } \\
\text { image k }\end{array}$ \\
\hline 9 & $\begin{array}{l}\text { 2004-01-30 } \\
\text { southern }\end{array}$ & 19:01:19 & $-0.3 ; 0.7 ; 0.7$ & intermediate & 24.8 & $\begin{array}{l}\mathrm{B} \text { [2007], } \\
\text { image } \mathrm{m}\end{array}$ \\
\hline 10 & $\begin{array}{l}2008-02-14 \\
\text { southern }\end{array}$ & 07:10:05 & $-0.1 ; 0.3 ; 0.3$ & compressed & 6.5 & $\begin{array}{l}\mathrm{B}[2010], \\
\text { image C }\end{array}$ \\
\hline 11 & $\begin{array}{l}2008-02-15 \\
\text { southern }\end{array}$ & $05: 32: 52$ & $-0.1 ; 0.1 ; 0.2$ & compressed & 6.5 & $\begin{array}{l}\mathrm{B}[2010], \\
\text { image D }\end{array}$ \\
\hline 12 & $\begin{array}{l}\text { 2011-04-01 } \\
\text { northern }\end{array}$ & 05:03:51 & $0.1 ; 0.2 ; 0.2$ & intermediate & -10.7 & $\begin{array}{l}\mathrm{B}[2014], \\
\text { visit } \mathrm{H} 1\end{array}$ \\
\hline 13 & $\begin{array}{l}\text { 2011-04-03 } \\
\text { northern }\end{array}$ & 03:23:19 & $0.0 ; 0.2 ; 0.1$ & intermediate & -10.8 & $\begin{array}{l}\mathrm{B}[2014] \\
\text { visit } \mathrm{H} 2\end{array}$ \\
\hline 14 & $\begin{array}{l}\text { 2011-04-05 } \\
\text { northern }\end{array}$ & 06:30:29 & $-0.3 ;-0.9 ; 0.4$ & intermediate & -10.8 & $\begin{array}{l}\mathrm{B}[2014] \\
\text { visit } \mathrm{H} 3\end{array}$ \\
\hline 15 & $\begin{array}{l}\text { 2012-04-01 } \\
\text { northern }\end{array}$ & $10: 47: 15$ & $-0.2 ;-0.1 ; 0.2$ & intermediate & -15.5 & $\begin{array}{l}\mathrm{B}[2014], \\
\text { visit I5 }\end{array}$ \\
\hline
\end{tabular}

is the solar wind velocity. This time is equal to the time $t_{\mathrm{pc}}$ during which the other end of the open field line crosses the polar cap of length $L_{\mathrm{pc}}$ (for northward IMF at Saturn), moving from the dayside to the nightside. Thus

$L_{\text {tail }} / V_{\mathrm{sw}}=L_{\mathrm{pc}} / V_{\mathrm{pc}}$,

$L_{\text {tail }}=L_{\mathrm{pc}} V_{\mathrm{sw}} / V_{\mathrm{pc}}$,

where $V_{\mathrm{pc}}$ is the velocity of the open field lines across the polar cap. We also have

$V_{\mathrm{pc}}=E_{\mathrm{pc}} / B_{\mathrm{pc}}$,

where $E_{\mathrm{pc}}$ is the electric field in the polar cap, and $B_{\mathrm{pc}}$ is the average polar cap magnetic field. Also, $E_{\mathrm{pc}}=\Phi_{\mathrm{pc}} / L_{\mathrm{pc}}$, where $\Phi_{\mathrm{pc}}$ is the polar cap potential drop given by $\Phi_{\mathrm{pc}}=$ $k V_{\mathrm{sw}} W_{\text {tail }} B_{\mathrm{sw}}$, where $W_{\text {tail }}$ is the tail width to which the solar wind potential drop is applied, $k$ is the coefficient of IMF penetration as above, and $B_{\mathrm{sw}}$ is the IMF component perpendicular to $V_{\mathrm{sw}}$. Estimations show that $L_{\text {tail }} \sim 1500 R_{\mathrm{S}}$, where $R_{\mathrm{S}}=60268 \mathrm{~km}$ is Saturn's 1 bar equatorial radius (Cowley et al., 2004a, b).

Calculations of the magnetospheric magnetic field lines in the noon-midnight meridian plane are shown for southward IMF in Fig. S1 and for northward IMF in Fig. S2 (see the Supplement). Examples from these figures are presented here in Figs. 4 and 5. Figure $4 \mathrm{a}$ and $\mathrm{b}$ show cases $8 \mathrm{a}$ and 8b, respectively. Figure $5 \mathrm{a}$ and $\mathrm{b}$ show cases $10 \mathrm{a}$ and $10 \mathrm{~b}$, respectively. The red curves in Fig. 5a mark separatrices, i.e., lines dividing magnetic field lines of different topological types. In Figs. S1 and S2 in the Supplement the left column shows results for the open field model, while the right column shows results for the partially closed model. From Fig. S1 it follows that for northward IMF conditions the neutral line in the equatorial tail is located between $\sim 17.5$ and $\sim 35 R_{\mathrm{S}}$ with a mean value of $\sim 26 R_{\mathrm{S}}$. For southward IMF (Fig. S2) the 

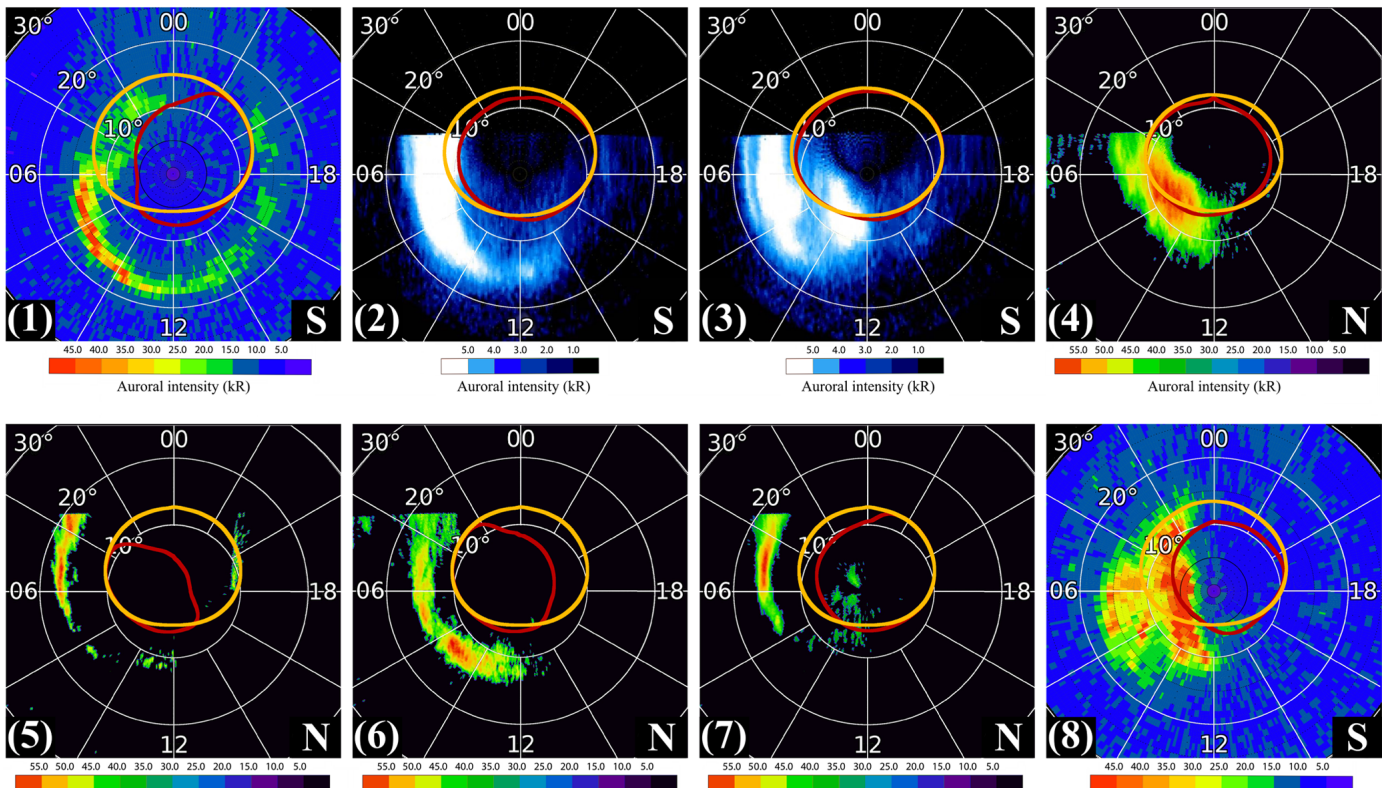

Auroral intensity (kR)

Auroral intensity (kR)

Auroral intensity (kR)

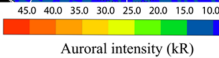

Open model

Partially closed model

Figure 2. Saturn UV auroral images obtained by the HST for southward IMF, with noon on the bottom and dusk on the right. The closed red curve in all figures in this paper shows the open flux boundary for the open magnetosphere model with $k=0.2$ using a multipole Saturn magnetic field (Burton et al., 2010) and a spheroidal ionosphere. The closed orange curve in all figures in this paper shows the open flux boundary for the partially closed model in which the IMF does not penetrate the magnetopause.
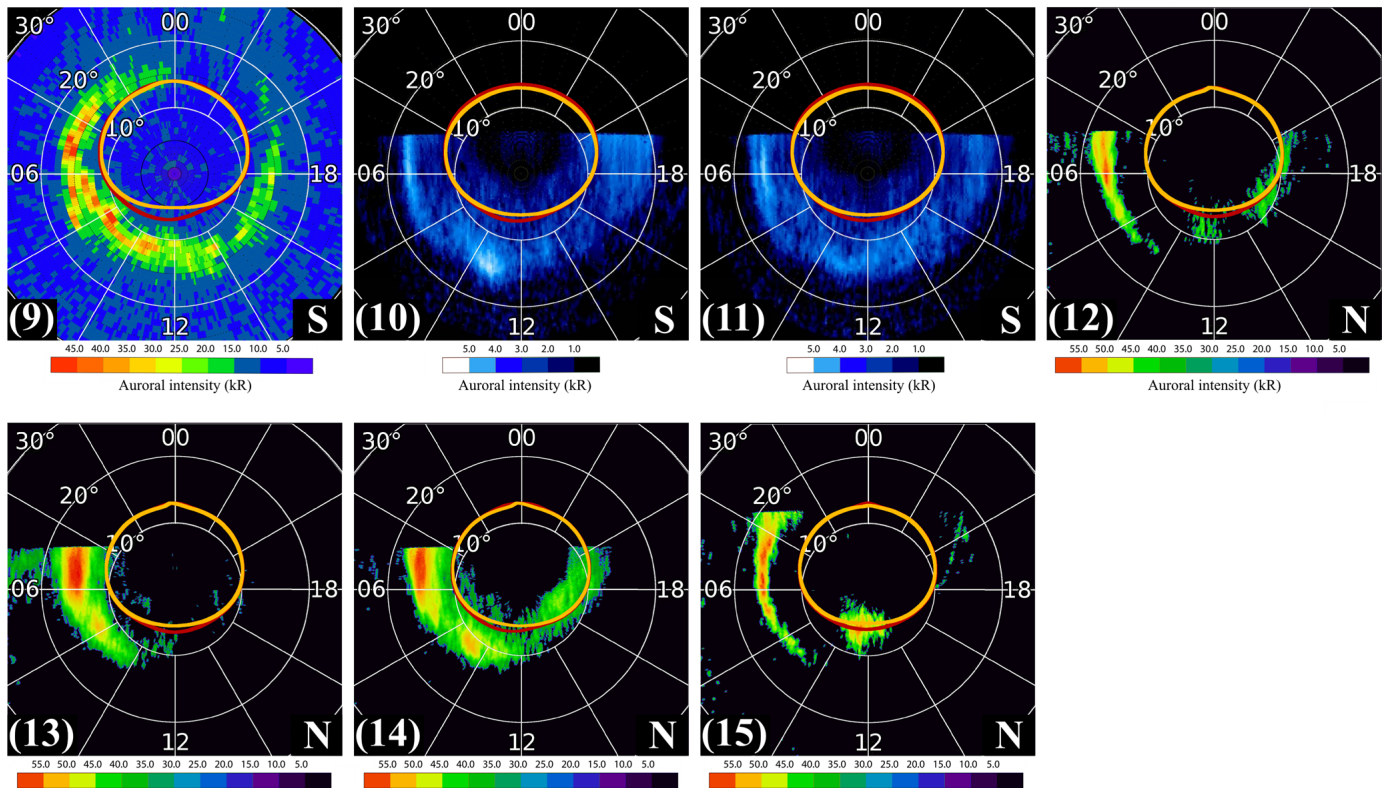

Auroral intensity $(\mathrm{kR})$

Open model

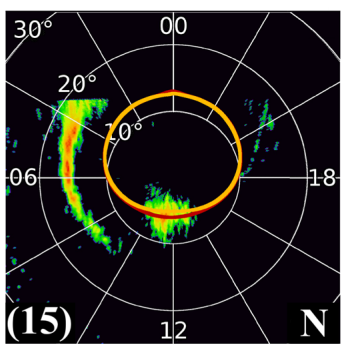

\begin{aligned} 55.0 \\ 50.0 \\ \hline Auroral intensity $(\mathrm{kR})\end{aligned}$

Partially closed model

Figure 3. Saturn UV auroral images obtained by the HST for northward IMF in the same format as Fig. 2. 

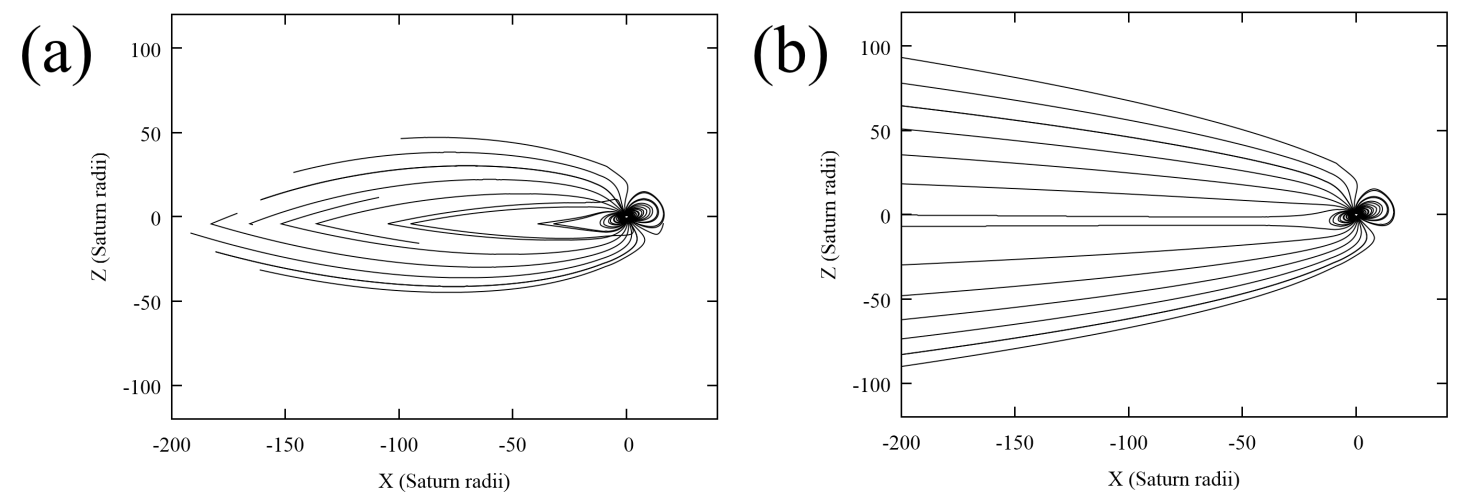

Figure 4. Projection onto the noon-midnight magnetospheric meridian of magnetic field lines starting from this plane (case 8 in Table 1); panel (a) shows results for the open magnetosphere model with penetration coefficient $k=0.2$, while panel (b) shows results for the partially closed model with $k=0$. The IMF vector is $(0.5 ;-2.0 ;-1.4) \mathrm{nT}$.
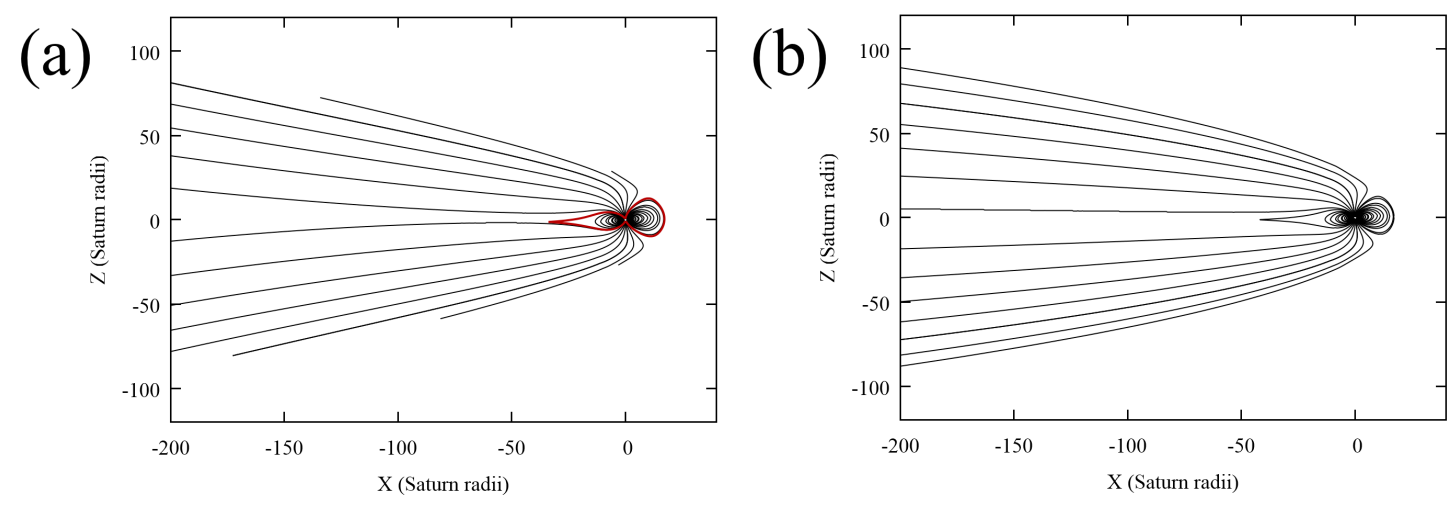

Figure 5. The same as in Fig. 4, but for case 10 from Table 1 with IMF vector $(-0.1 ; 0.3 ; 0.3)$ nT. The red lines in panel (a) mark separatrices.

situation is more complicated (e.g., Belenkaya et al., 2014), since the neutral line does not exist either at the dayside magnetopause or in the tail, but neutral points occur in the cusps in the open model. For southward IMF, the tail length determined by the intersection of the last open field line with the magnetopause could be at an even greater distance than for northward IMF.

For the partially closed model with $k=0$, the tail length is much shorter. From calculations of the model field line structure for $k=0$ it follows that the boundary between open (through the tail) and closed field lines, which can be considered as a measure of the tail length in this case (see Fig. 1), is located somewhere between $X=-20$ and $-80 R_{\mathrm{S}}$ (see the right-hand columns of Figs. S1 and S2). In the Earth's magnetosphere, the nightside $X$ line where reconnection takes place during substorms is located between 10 and $30 R_{\mathrm{E}}$ (where $R_{\mathrm{E}}$ is Earth's radius equal to $6371 \mathrm{~km}$ ). Since the ratio of the magnetospheric scales of these two planets is $\sim 2.5$, the corresponding boundary between open and closed field lines should be placed in Saturn's tail at distances of $25-75 R_{\mathrm{S}}$ from Saturn's center in accordance with the model calculations.

\section{Southward and northward IMF}

Interaction of the solar wind and IMF with Saturn's magnetosphere in the case in which the IMF does not penetrate the magnetopause has some similarities with the magnetized plasma flow past nonmagnetized Venus or comets. At Saturn for the case where $k=0$, reconnection can act at the end of the equatorial tail as indicated in Fig. 1. Zhang et al. (2012) describe reconnection in the tail of Venus, while Jia et al. (2009) similarly discuss the tail of comet 2P/Encke. In spite of the fact that Saturn possesses a strong magnetic field, the reconnection in its short tail for $k=0$ resembles the effects in these unmagnetized systems.

Smith et al. (2016) analyzed 2094 observations of reconnection in Saturn's magnetotail, finding that the night neutral line is located between 20 and $30 R_{\mathrm{S}}$ from the planet's center. These events were found in Cassini data limited to a radial distance within $68 R_{\mathrm{S}}$ from the planet. Calculations in the paraboloid model for northward IMF, as noted above, give the position of the night neutral line (separatrix) in the equatorial tail between $\sim 17.5$ and $35 R_{\mathrm{S}}$ in good accordance with these observations. Arridge et al. (2015) also described observations of a tail reconnection event observed over an in- 


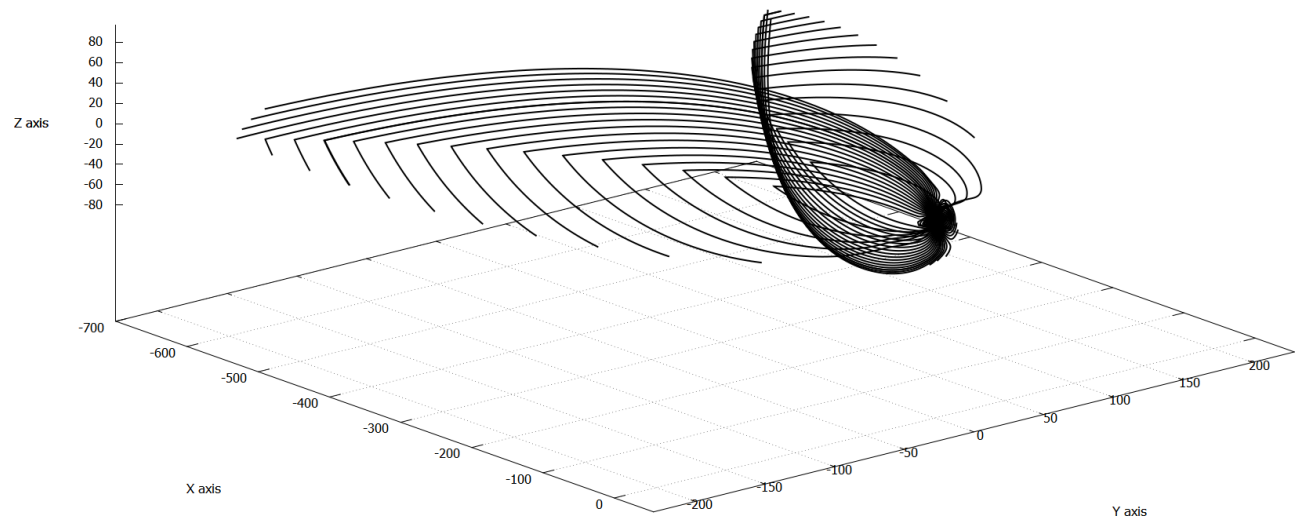

Figure 6. Example of the 3-D structure of Saturn's magnetosphere for southward IMF in case 1 (see Table 1).

terval of $19 \mathrm{~h}$, with a diffusion region at a radial distance of $29 R_{\mathrm{S}}$. This example directly shows the closing of open flux in Saturn's tail.

The first direct evidence for reconnection in Saturn's tail, a dipolarization event observed by Cassini, was reported by Bunce et al. (2005). Jackman et al. (2007, 2008) and Jackman (2015) also described reconnection effects in the tail, while Arridge et al. (2015) reported the direct crossing of reconnection diffusion region by Cassini as outlined above. Cowley et al. (2015) also argued that the down-tail spatial scale of plasmoids determined from Cassini data could be much less than their true size, thus potentially providing an explanation for why the mass loss carried by plasmoids appears insufficient to balance the Enceladus plasma source.

Here we have shown that the two models of solar windmagnetosphere interaction considered, the open model and the partially closed model, give very similar open field line areas in the high-latitude ionosphere for northward IMF but different for southward IMF. For both models the angular velocity change at the open flux boundary will lead to the formation of strong upward field-aligned currents. For northward IMF (Fig. 3) these currents almost coincide and are located close to the oval, while for southward IMF (Fig. 2) the situation is more complicated, with the open model giving field-aligned currents that could more likely be interpreted as connected with the poleward edge of the oval emissions than those for the partially closed magnetosphere. In Fig. 2, for example, the open model appears preferable in cases 1 , 2,5 , and 8 , for which the open-closed boundary for the open model (red curve) is located closer to the poleward edge of the auroral oval than for the partially-closed model (orange curve). In making these comparisons between model and image boundaries, we note that the poleward boundary of the auroras at a particular local time has been taken as the usually well-defined point at which the emission intensity increases well above near-background values, the latter being shown as blue in cases 1, 8, and 9 in Figs. 2 and 3 and as black in the other images. The background intensity is typically a few $\mathrm{kR}$, depending somewhat on instrumental and physical conditions. The corresponding auroral intensity at the effective boundary is then also somewhat variable at $\sim 15 \mathrm{kR}$ in plots 1 and 8 in Fig. 2, $\sim 3 \mathrm{kR}$ in plots 2 and 3, and $\sim 30 \mathrm{kR}$ in plots 4-7. However, since the gradient in emission intensity at the boundary is usually sharp, as can be seen in the images, these differences will not strongly affect the results.

Smith et al. (2016) show that reconnection in Saturn's magnetotail generally occurs sporadically. We emphasize here that reconnection in the tail takes place only for northward IMF, since for southward IMF reconnection must happen in the cusps. Figure 6 demonstrates 3-D reconnection at the neutral points located in both cusp regions under southward IMF conditions $(0.0,-0.4,-0.4) \mathrm{nT}$ measured during case 1 . The $3-\mathrm{D}$ reconnection at the neutral points is characterized by open field lines from the northern polar cap mapping to the southern magnetopause, while open field lines from the northern magnetopause map to the southern polar cap (see the "3-D Lines Animation" in the Supplement). Convection across the pole will be sunward. Figure 7 shows the principal difference in the Kronian magnetospheric magnetic field structure caused by the IMF turning to the northward direction. Calculations were performed for case 9 when the IMF had the components $(0.3,0.7,0.7) \mathrm{nT}$. The magnetosphere under such conditions is similar to the Dungey (1961) model for southward IMF interacting with the Earth's magnetospheric field. The reconnection is of a 2-D type and occurs at the dayside and nightside neutral points connected by the low-latitude quasi-neutral line. Open field lines from the northern (southern) polar cap intersect the northern (southern) magnetopause. Convection across the pole will be anti-sunward. Reconnection in the tail is associated with field dipolarization on one side of the neutral point and plasmoid formation on the other. On the noon magnetopause FTEs could arise for northward IMF conditions. The absence of FTE observations at Saturn's noon magnetopause (as reported, e.g., by Huddleston et al., 1997; Lai et al., 2012) could mean that the partially closed magnetosphere model may be realized for northward IMF. According to Fig. 1b, dayside reconnection should then be absent, 


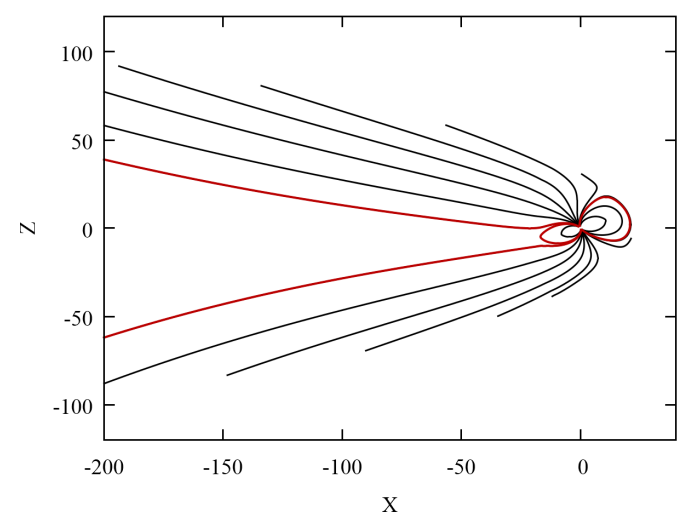

Figure 7. Example of the 2-D structure of Saturn's magnetosphere for northward IMF in case 9 (see Table 1). Separatrices are shown in red.

while in the tail some kind of reconnection may occur. At the end of the tail as a result of reconnection between open field lines going through the northern and southern lobes, closed and interplanetary field lines arise. As a consequence, field dipolarization and plasmoid generation could be observed, as supported by Cassini observations. It should be noted, however, that some observations of reconnection at the dayside magnetopause for northward IMF do nevertheless exist (e.g., McAndrews et al., 2008). Meredith et al. (2014) studied the northern polar cap and found that post-noon auroral arcs exist for northward IMF, but not for southward IMF. They suggested that these were associated with low-latitude reconnection occurring for northward IMF. Their location in the dusk sector was also suggested to be due to the small velocity shear at the dusk magnetopause, which promotes the occurrence of reconnection at the boundary. The images in Figs. 2 and 3 in the present paper generally show similar differences. Taking this argument into account, we conclude that the open model is probably appropriate for northward IMF also. Meredith et al. (2014) explained that the absence of FTEs at the Kronian magnetopause was likely due to the different timescales of such phenomena relative to the case of Earth due to the much larger magnetospheric length scales involved. As noted above, the open-closed field line boundaries calculated for the two models using the paraboloid model do not show great difference for northward IMF. For this reason, we cannot definitely determine which model is dominant in this case.

For southward IMF, this study provides some evidence that the open magnetospheric model gives a better explanation for the observed dawn-dusk asymmetry of the area bounded by the auroral oval than the partially closed model. For this reason, we conclude that for southward IMF, reconnection occurring in the cusps may be more significant for Saturn's magnetosphere. We note that McAndrews et al. (2008) reported observations indicating the presence of reconnection poleward of the cusp in the form of heated field-aligned elec- tron flows observed outside the magnetopause under conditions of low magnetic shear. Palmaerts et al. (2016) noted that observations of high-latitude aurora show that reconnection near the cusp often occurs at Saturn under southward IMF conditions.

For Earth, the plasma depletion layer in the magnetosheath just outside the dayside magnetopause is thinner for southward IMF when reconnection occurs at the noon magnetopause (we note that the internal planetary fields at Earth and Saturn are oppositely directed). The plasma density decreases and magnetic field strength increases within it. An investigation of Cassini measurements in Saturn's magnetosheath by Masters et al. (2014) found that in this case there is no difference in the plasma depletion layer for northward and southward IMF, which is contrary to the results of related Voyager measurements that indicated an IMF effect (Violante et al., 1995). Masters et al. (2014) inferred that reconnection at the dayside magnetopause is not effective at Saturn. We emphasize that this may concern only northward IMF conditions, but not necessarily southward IMF conditions. Thus, the conclusions of Masters et al. (2014) do not mean that the reconnection in cusps, which is characteristic of southward IMF conditions, is not effective at Saturn. Masters et al. (2014) noted that contrary to the case of Earth, magnetosheath flow is predominant over Saturn's poles due to magnetospheric flattening. In this situation the role of cusp reconnection for southward IMF could be enhanced at Saturn.

Our calculations using the paraboloid model show that the boundaries between open and closed field lines for the open and partially closed magnetospheric models are located close to each other for northward IMF, but not for southward IMF if $\left|B_{z}\right|>\left|B_{x}\right|$, where $B_{x}$ and $B_{z}$ are the radial and north-south IMF components, respectively (specific magnetospheric structures arising for $\left|B_{z}\right|<\left|B_{x}\right|$ in the terrestrial magnetosphere are considered by Belenkaya, 1998). For cases in which the open model appears preferable (cases 1, 2,5 , and 8), the north-south component was greater or equal to the radial. The other cases are not included because for cases 3 and 4 the boundaries for both models coincide, for case 6 there are no emissions in the region where the boundaries differ from each other, and in case 7 emissions occur inside both boundaries.

In addition to visual inspection of the data, in the remaining four cases for southward IMF we have also made quantitative comparisons of the latitudinal position of the model boundaries with the poleward boundary of the auroras to verify which model brings closer agreement. The boundaries were approximated with cubic splines and the calculations carried out with a longitudinal resolution of $1^{\circ}$. We find for case 1 , for example, that the mean of the absolute error is $\sim 3.7^{\circ}$ for the open model and $\sim 5.3^{\circ}$ for the partially closed, thus verifying the conclusions of visual inspection. 

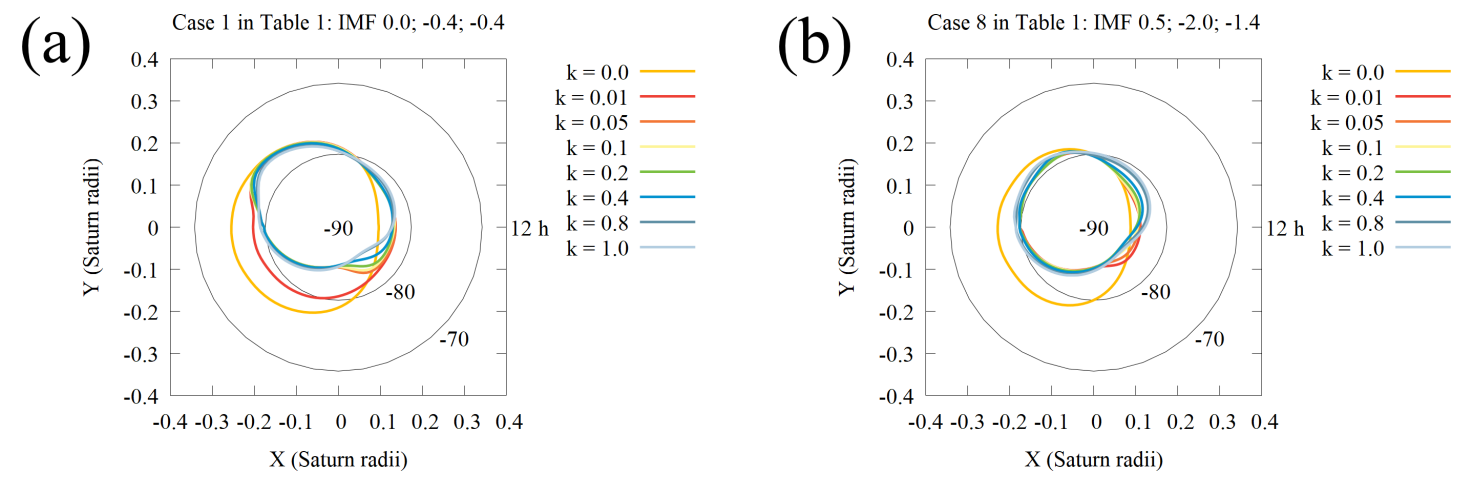

Figure 8. Ionospheric open field line area calculated for cases (a) 1 and (b) 8 (see Table 1) for different values of the IMF penetration coefficient into the Kronian magnetosphere: $k=0.0,0.01,0.05,0.1,0.2,0.4,0.8$, and $1.0(k=0$ corresponds to the partially closed model, $k \neq 0$ to the open model).

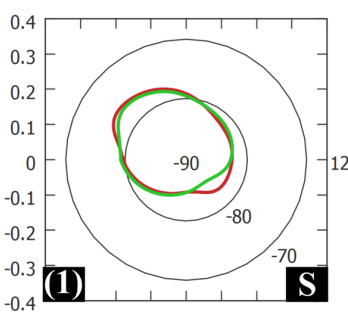

$-0.4-0.3-0.2-0.1 \quad 0 \quad 0.1 \quad 0.2 \quad 0.3 \quad 0.4$

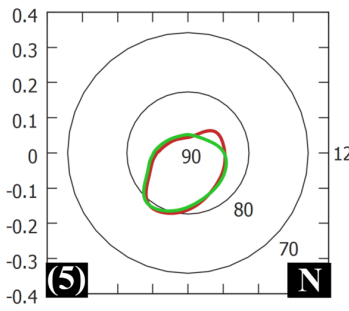

$\begin{array}{llllll}-0.4-0.3-0.2-0.1 & 0 & 0.1 & 0.2 & 0.3 & 0.4\end{array}$

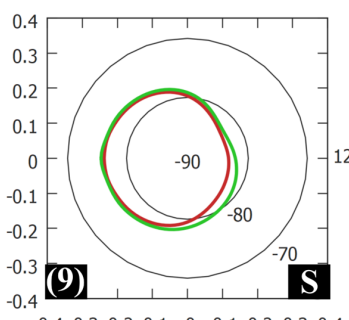

$\begin{array}{llllll}-0.4-0.3-0.2-0.1 & 0 & 0.1 & 0.2 & 0.3 & 0.4\end{array}$

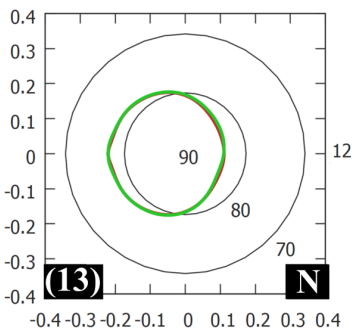

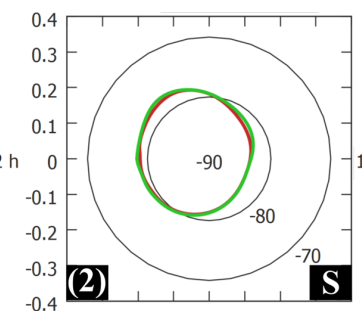

$0.4-0.3-0.2-0.1 \quad 0 \quad 0.10 .20 .3 \quad 0.4$

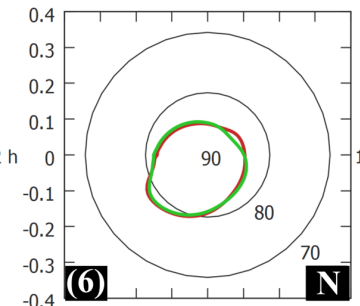

$\begin{array}{lllllll}-0.4-0.3-0.2-0.1 & 0 & 0.1 & 0.2 & 0.3 & 0.4\end{array}$
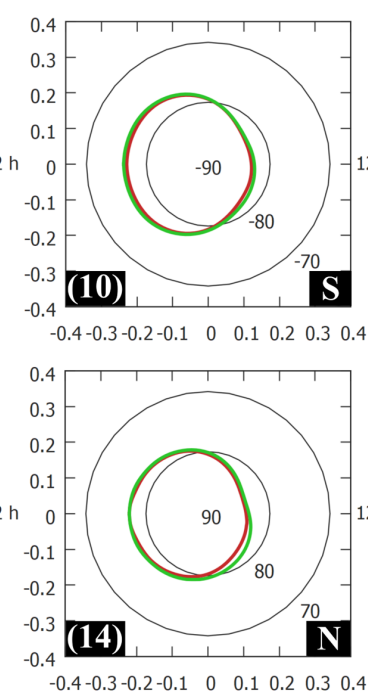
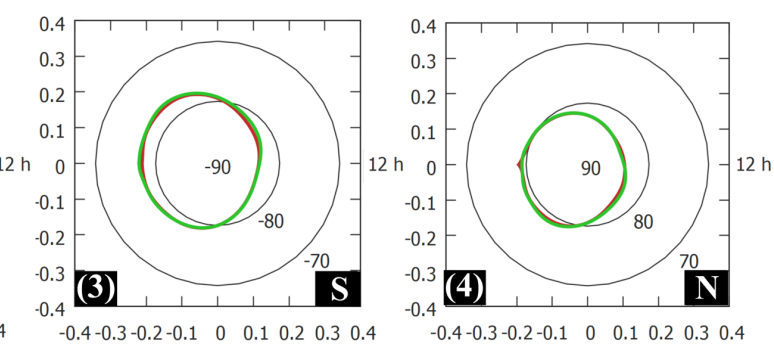

$\begin{array}{llllll}-0.4-0.3-0.2-0.1 & 0 & 0.1 & 0.2 & 0.3 & 0.4\end{array}$
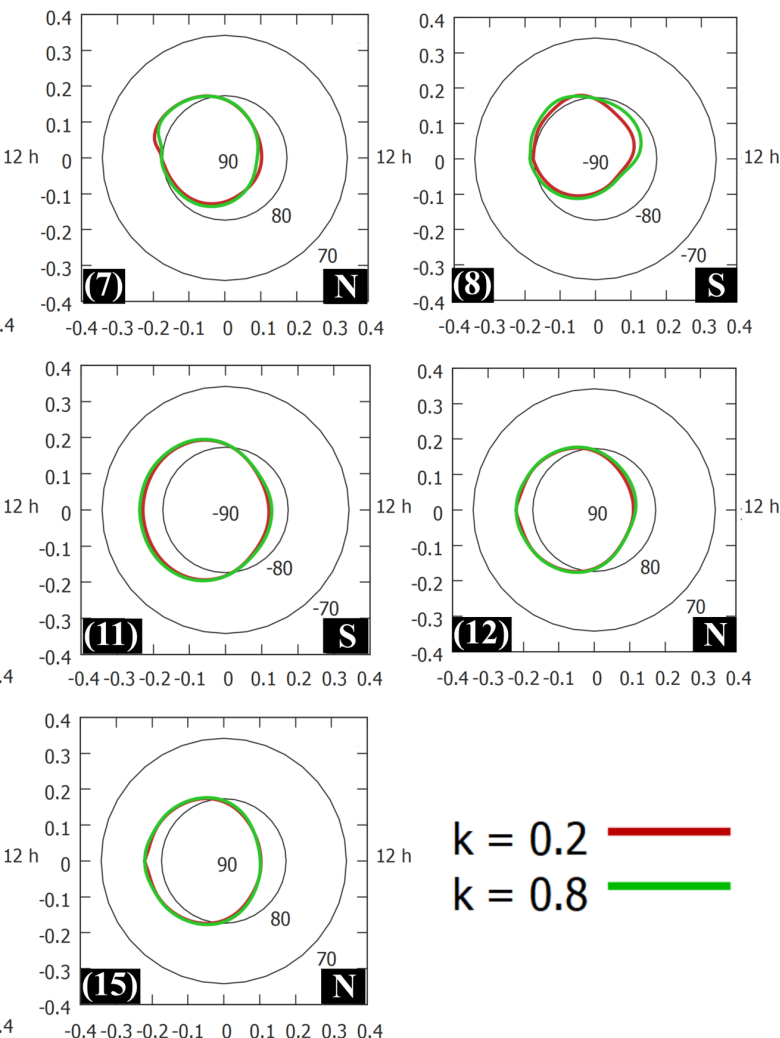

Figure 9. Ionospheric open field line area calculated for all cases from Table 1 for different values of the IMF penetration coefficient into the Kronian magnetosphere; $k=0.2$ (red curve) and $k=0.8$ (green curve). 

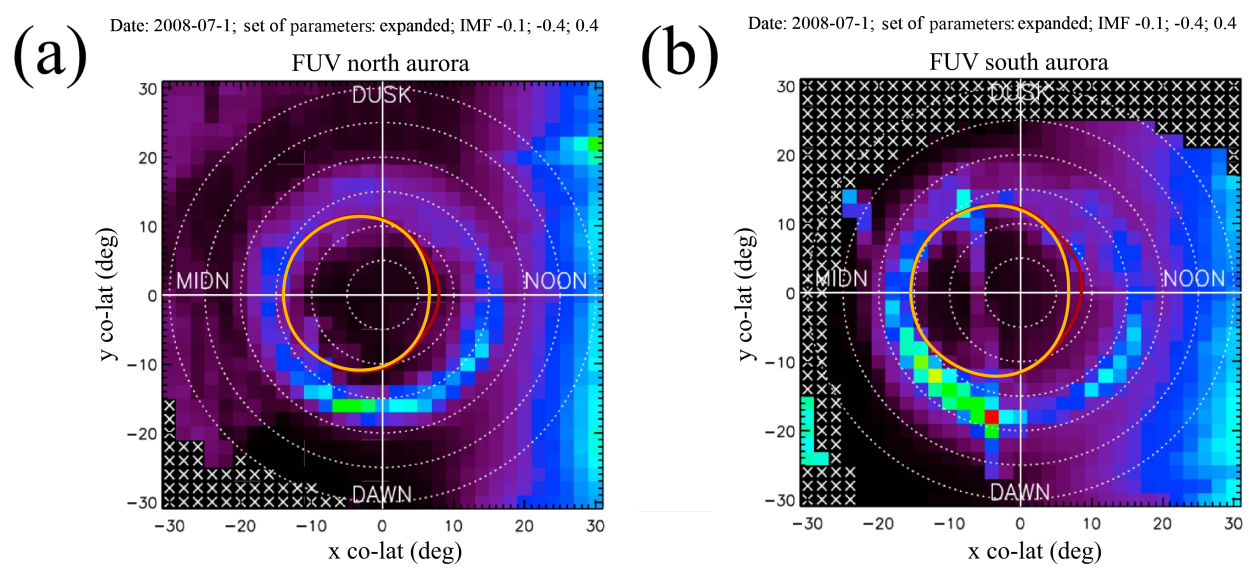

Figure 10. Comparison of the statistical UV auroral oval obtained by Carbary (2012) from Cassini UVIS data from 2007-2009 with model calculations of the open-closed field line boundary for (a) the northern and (b) the southern hemispheres. The model time was selected to be 1 July 2008 (the middle of the interval of Cassini observations), and the set of the model parameters corresponds to the expanded state of the magnetosphere, i.e., low solar wind dynamic pressure (see text). The northward-directed IMF vector assumed has components $(-0.1,-0.4$, 0.4) nT. The red line marks the open flux boundary for the open model, while the orange line is for the partially closed model.
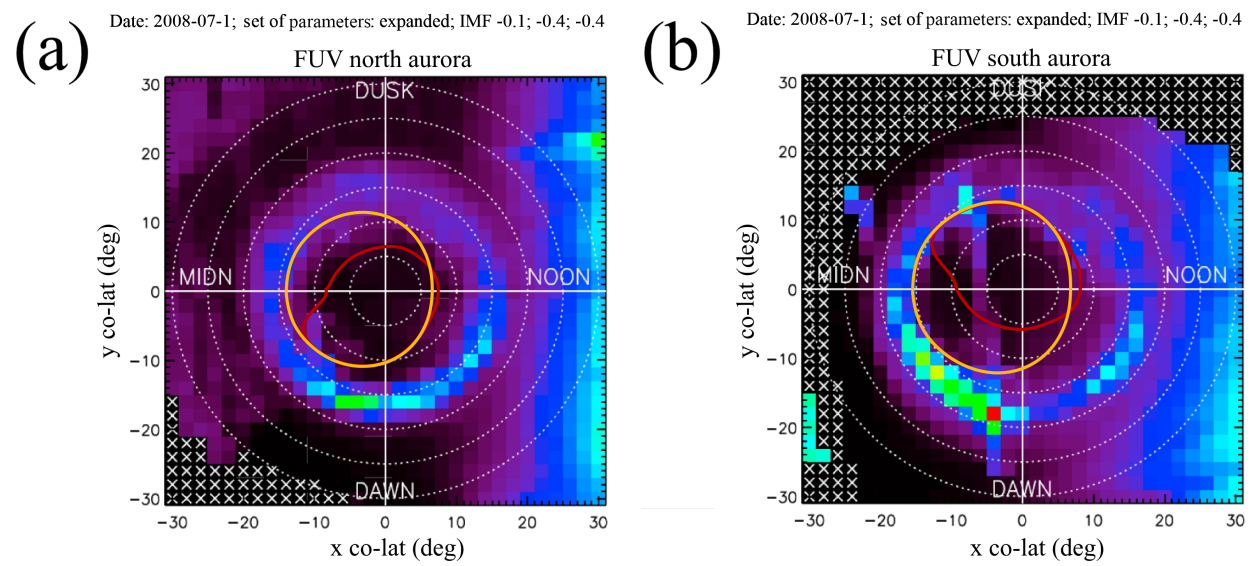

Figure 11. As for Fig. 10, but for a southward IMF vector $(-0.1,-0.4,-0.4) \mathrm{nT}$.

\section{Discussion}

Here we briefly discuss the properties of the paraboloid model and some results obtained from this model. Figure 8 presents the ionospheric open field line area for case 1 (Fig. 8a) and case 8 (Fig. 8b) from Table 1 calculated for $k=0.0,0.01,0.05,0.1,0.2,0.4,0.8$, and 1.0. These representative values of the IMF penetration coefficient allow us to conclude that starting from $k \sim 0.05$, the ionospheric open-closed boundary practically does not change. We chose $k=0.2$, similar to the case of the Earth, because mapping of the open-closed boundary to the ionosphere does not allow us to determine the correct value of $k$, since variation of the value $k$ over the region $0.05<k<1$ does not influence our result.

This conclusion is supported by Fig. 9, in which for all cases from Table 1 open fluxes are calculated for $k=0.2$ (red lines) and $k=0.8$ (green lines). We see that these lines are almost coincident with each other, and that for northward IMF (cases 9-15), in analogy with southward IMF for the Earth, the open flux area is almost constant. For southward IMF (cases 1-8), also in analogy with northward IMF for the Earth, the open flux becomes smaller and only a part of the open flux for northward IMF, as the other part of it transfers to IMF lines penetrating the magnetosphere.

The paraboloid model has been used for different magnetized planets and has given results that allowed us to explain a lot of observational data. In particular, it has been extensively applied to Saturn (Alexeev et al., 2006; Belenkaya et al., 2006b, 2007, 2008, 2010, 2011, 2013, 2014). The advantages of the model relate to its block structure; i.e., the magnetic field of each magnetospheric current system is calculated using its own program (block). The condition $\operatorname{div} \boldsymbol{B}=0$ is valid everywhere in the model domain, where $\boldsymbol{B}$ is the total magnetospheric field. In addition, at the magnetopause each magnetospheric magnetic field source has a normal compo- 
nent equal to zero. Magnetospheric model parameters depend on both outer and inner magnetospheric conditions. The paraboloid model is the only global model that currently gives the magnetospheric magnetic field everywhere inside the magnetopause.

The limitations of the paraboloid model are the following. It is a static model describing the quasi-equilibrium magnetospheric state. For this reason, it does not reflect shortterm variations in the solar wind and its magnetic field. It gives some average magnetospheric state corresponding to the concurrent conditions in interplanetary space. As the model magnetopause is a paraboloid of revolution, its radius in the distant tail is greater than the observed value. For the same reason, the asymmetry of the real magnetopause is neglected.

For the Earth, the results obtained using the paraboloid model indicate an ionospheric open-closed boundary usually located close to the poleward auroral oval edge for southward IMF, but shifted to higher latitudes for northward IMF. Similar effects also occur at Saturn, but due to the antiparallel directions of the dipole moments of these planets, southward and northward IMF change their roles.

We have also compared the statistical positions of the Kronian auroral ovals in both polar caps determined from Cassini UVIS data from 2007 to 2009 by Carbary (2012) with the open-closed boundaries calculated using the paraboloid model for the open (red curve) and partially closed (orange curve) configurations. For calculations we took an arbitrary time close to the middle of this interval (1 July 2008) and an arbitrary typical northward IMF $(-0.1,-0.4$, $0.4) \mathrm{nT}$ (Fig. 10) and southward IMF (-0.1, -0.4, -0.4) nT (Fig. 11). In panels (a) and (b) of Figs. 10 and 11 we show the northern and southern polar hemispheres, respectively. The statistical pictures are taken from Fig. 1 of Carbary (2012). We see that for northward IMF (Fig. 10) both curves almost coincide, except on the dayside, and are located close to the poleward edge of the oval in the midnight, dawn, and dusk sectors. At noon they are located poleward of the emission in both hemispheres. For southward IMF (Fig. 11), the same is true for the partially closed model (orange curve), while the open model (red curve) gives smaller open flux. In the statistical sense, the contribution of southward IMF to Saturn's magnetosphere is less than for northward IMF (the size of the open "window" at the magnetopause, the polar cap area and voltage, and related quantities), so in the statistical picture northward IMF plays the main role. For these calculations we took the model parameter set corresponding to the expanded state of the magnetosphere, as on average low solar wind dynamic pressure is more typical. The set of parameters for the expanded magnetosphere is as follows: distance to the magnetopause subsolar point $R_{\mathrm{ss}}=28 R_{\mathrm{S}}$, distance to the outer edge of the ring current $R_{\mathrm{rc} 1}=24.5 R_{\mathrm{S}}$, distance to the inner edge of the ring current $R_{\mathrm{rc} 2}=6.5 R_{\mathrm{S}}$, radial field at the outer edge of the ring current $B_{\mathrm{rcl}}=2.2 \mathrm{nT}$, distance to the inner edge of the tail current sheet $R_{2}=22.45 R_{\mathrm{S}}$, and the magnetic field of the tail current system at the inner edge of the tail current sheet $B_{\mathrm{t}}=5.3 \mathrm{nT}$ (Belenkaya et al., 2008). Quantitative comparison of the calculated orange open-closed boundaries in the two hemispheres with the poleward auroral boundaries presented in Carbary's (2012) Fig. 3 yields the following latitudinal deviations. For the northern polar cap at noon $6-7^{\circ}$, at dawn $4-5^{\circ}$, at midnight $1-2^{\circ}$, and at dusk $1-2^{\circ}$. For the southern polar cap the deviations at noon are $5-7^{\circ}$, at dawn $4-5^{\circ}$, at midnight $0^{\circ}$, and at dusk $0-2^{\circ}$.

\section{Conclusions}

Here we have investigated one aspect of the interaction between the solar wind and the outer planets in the solar system, concentrating particularly on the case of Saturn. Our results show that this phenomenon is rather complex and depends significantly on the components of the IMF and their relationships.

Masters et al. (2014) and the references therein state that the power of auroral emissions at Saturn does not demonstrate clear dependence on the IMF direction. Here we have shown that at least the modeled open flux area at the ionospheric level is sensitive to strongly southward IMF. Some evidence of such dependency is found in corresponding UV images obtained by the HST. Using Cassini IMF data, HST UV auroral images, and paraboloid model calculations, we find that penetration of the IMF into the magnetosphere probably occurs for strong southward IMF. For northward IMF and IMF with a strong radial component, the approach presented does not allow us to make a definite conclusion about which of two models, open or partially closed, is preferable for Saturn; however, observations show that for southward IMF high-latitude reconnection does occur (e.g., Palmaerts et al., 2016).

Code availability. Those who would like to work with the paraboloid model may contact us (Igor I. Alexeev at alexeev@dec1.sinp.msu.ru and/or Vladimir V. Kalegaev at klg@dec1.sinp.msu.ru).

\section{The Supplement related to this article is available online at https://doi.org/10.5194/angeo-35-1293-2017- supplement.}

Competing interests. The authors declare that they have no conflict of interest.

Acknowledgements. Work at the Federal State Budget Educational Institution of Higher Education M.V. Lomonosov Moscow State University, Skobeltsyn Institute of Nuclear Physics (SINP MSU) 
was partially supported by the Ministry of Education and Science of the Russian Federation (grant RFMEFI61617X0084).

The topical editor, Elias Roussos, thanks James Carbary and one anonymous referee for help in evaluating this paper.

\section{References}

Alexeev, I. I.: The penetration of interplanetary magnetic and electric fields into the magnetosphere, J. Geomagn. Geoelectr., 38, 1199-1221, https://doi.org/10.5636/jgg.38.1199, 1986.

Alexeev, I. I. and Belenkaya, E. S.: Modeling of the Jovian Magnetosphere, Ann. Geophys., 23, 809-826, https://doi.org/10.5194/angeo-23-809-2005, 2005.

Alexeev, I. I., Belenkaya, E. S., and Sibeck, D. G.: Open field lines in the closed model of the magnetosphere, Geomagn. Aeron.+, 38, 9-18, 1998 (in Russian).

Alexeev, I. I., Kalegaev, V. V., Belenkaya, E. S., Bobrovnikov, S. Y., Bunce, E. J., Cowley, S. W. H., and Nichols, J. D.: A global magnetic model of Saturn's magnetosphere and a comparison with Cassini SOI data, Geophys. Res. Lett., 33, L08101, https://doi.org/10.1029/2006g1025896, 2006.

Alfvén, H.: Note on the "auroral oval”, J. Geophys. Res., 72, 35033503, https://doi.org/10.1029/jz072i013p03503, 1967.

Anderson, B. J., Phan, T. D., and Fuselier, S. A.: Relationships between plasma depletion and subsolar reconnection, J. Geophys. Res.-Space, 102, 9531-9542, https://doi.org/10.1029/97ja00173, 1997.

Arridge, C. S., Eastwood, J. P., Jackman, C. M., Poh, G. K., Slavin, J. A., Thomsen, M. F., André, N., Jia, X., Kidder, A., Lamy, L., Radioti, A., Reisenfeld, D. B., Sergis, N., Volwerk, M., Walsh, A. P., Zarka, P., Coates, A. J., and Dougherty, M. K.: Cassini in situ observations of long-duration magnetic reconnection in Saturn's magnetotail, Nat. Phys., 12, 268-271, https://doi.org/10.1038/nphys3565, 2015.

Badman, S. V., Masters, A., Hasegawa, H., Fujimoto, M., Radioti, A., Grodent, D., Sergis, N., Dougherty, M. K., and Coates, A. J.: Bursty magnetic reconnection at Saturn's magnetopause, Geophys. Res. Lett., 40, 1027-1031, https://doi.org/10.1002/grl.50199, 2013.

Belenkaya, E. S.: Reconnection modes for near-radial interplanetary magnetic field, J. Geophys. Res.-Space, 103, 26487-26494, https://doi.org/10.1029/98ja02270, 1998.

Belenkaya, E. S.: The Jovian magnetospheric magnetic and electric fields: Effects of the interplanetary magnetic field, Planet. Space Sci., 52, 499-511, https://doi.org/10.1016/j.pss.2003.06.008, 2004.

Belenkaya, E. S.: Magnetospheres of planets with an intrinsic magnetic field, Phys.-Usp.+, 52, 765-788, https://doi.org/10.3367/ufne.0179.200908a.0809, 2009.

Belenkaya, E. S. and Khodachenko, M.: Accretion and Current Discs Controlled by Strong Magnetic Field, International Journal of Astronomy and Astrophysics, 2, 81-96, https://doi.org/10.4236/ijaa.2012.22012, 2012.

Belenkaya, E. S., Bespalov, P. A., Davydenko, S. S., and Kalegaev, V. V.: Magnetic field influence on aurorae and the Jovian plasma disk radial structure, Ann. Geophys., 24, 973-988, https://doi.org/10.5194/angeo-24-973-2006, 2006a.
Belenkaya, E. S., Alexeev, I. I., Kalegaev, V. V., and Blokhina, M. S.: Definition of Saturn's magnetospheric model parameters for the Pioneer 11 flyby, Ann. Geophys., 24, 1145-1156, https://doi.org/10.5194/angeo-24-1145-2006, 2006 b.

Belenkaya, E. S., Alexeev, I. I., Blokhina, M. S., Cowley, S. W. H., Badman, S. V., Kalegaev, V. V., and Grigoryan, M. S.: IMF dependence of the open-closed field line boundary in Saturn's ionosphere, and its relation to the UV auroral oval observed by the Hubble Space Telescope, Ann. Geophys., 25, 1215-1226, https://doi.org/10.5194/angeo-25-1215-2007, 2007.

Belenkaya, E. S., Cowley, S. W. H., Badman, S. V., Blokhina, M. S., and Kalegaev, V. V.: Dependence of the open-closed field line boundary in Saturn's ionosphere on both the IMF and solar wind dynamic pressure: comparison with the UV auroral oval observed by the HST, Ann. Geophys., 26, 159-166, https://doi.org/10.5194/angeo-26-159-2008, 2008.

Belenkaya, E. S., Alexeev, I. I., Blokhina, M. S., Bunce, E. J., Cowley, S. W. H., Nichols, J. D., Kalegaev, V. V., Petrov, V. G., and Provan, G.: IMF dependence of Saturn's auroras: modelling study of HST and Cassini data from 12-15 February 2008, Ann. Geophys., 28, 1559-1570, https://doi.org/10.5194/angeo28-1559-2010, 2010.

Belenkaya, E. S., Cowley, S. W. H., Nichols, J. D., Blokhina, M. S., and Kalegaev, V. V.: Magnetospheric mapping of the dayside UV auroral oval at Saturn using simultaneous HST images, Cassini IMF data, and a global magnetic field model, Ann. Geophys., 29, 1233-1246, https://doi.org/10.5194/angeo-29-1233-2011, 2011.

Belenkaya, E. S., Cowley, S. W. H., Kalegaev, V. V., Barinov, O. G., and Barinova, W. O.: Magnetic interconnection of Saturn's polar regions: comparison of modelling results with Hubble Space Telescope UV auroral images, Ann. Geophys., 31, 1447-1458, https://doi.org/10.5194/angeo-31-1447-2013, 2013.

Belenkaya, E. S., Cowley, S. W. H., Meredith, C. J., Nichols, J. D., Kalegaev, V. V., Alexeev, I. I., Barinov, O. G., Barinova, W. O., and Blokhina, M. S.: Magnetospheric magnetic field modelling for the 2011 and 2012 HST Saturn aurora campaigns - implications for auroral source regions, Ann. Geophys., 32, 689-704, https://doi.org/10.5194/angeo-32-689-2014, 2014.

Bunce, E. J., Cowley, S. W. H., Wright, D. M., Coates, A. G., Dougherty, M. K., Krupp, N., Kurth, W. S., and Rymer, A. M.: In situ observations of a solar wind compression-induced hot plasma injection in Saturn's tail, Geophys. Res. Lett., 32, L20S04, https://doi.org/10.1029/2005gl022888, 2005.

Bunce, E. J., Arridge, C. S., Clarke, J. T.and Coates, A. G., Cowley, S. W. H an Dougherty, M. K., G'erard, J. C., Grodent, D., Hansen, K. C., Nichols, J. D., Southwood, D. J., and Talboys, D. L.: Origin of Saturn's aurora: Simultaneous observations by Cassini and the Hubble Space Telescope, J. Geophys. Res.Space, 113, A09209, https://doi.org/10.1029/2008ja013257, 2008.

Burton, M. E., Dougherty, M. K., and Russell, C. T.: Saturn's internal planetary magnetic field, Geophys. Res. Lett., 37, L24105, https://doi.org/10.1029/2010g1045148, 2010.

Carbary, J. F.: The morphology of Saturn's ultraviolet aurora, J. Geophys. Res.-Space, 117, A06210, https://doi.org/10.1029/2012ja017670, 2012.

Clarke, J. T.: Auroral Processes on Jupiter and Saturn, in: Auroral Phenomenology and Magnetospheric Processes: Earth And Other Planets, edited by: Keiling, A., Donovan, E., Bage- 
nal, F., and Karlsson, T., American Geophysical Union, Geophysical Monograph Series 197, 113-122, Washington, D. C., https://doi.org/10.1029/2011GM001199, 2012.

Clarke, J. T., Grodent, D., Cowley, S. W. H., Bunce, E. J., Zarka, P., Connerney, J. E. P., and Saton, T.: Jupiter's aurora, in: Jupiter. The planet, satellites and magnetosphere, edited by: Bagenal, F., Dowling, T., and McKinnon, W., Cambridge Planetary Science, 639-670, Cambridge University Press, Cambridge, UK, 2004.

Clarke, J. T., Nichols, J. D., Ge'rard, J. C., Grodent, D., Hansen, K. C., Kurth, W., Gladstone, G. R., Duval, J., Wannawichian, S., Bunce, E. J., Cowley, S. W. H., Crary, F., Dougherty, M. K., Burton, M. E., Lamy, L., Mitchell, D., Pryor, W., Retherford, K., Stallard, T., Zieger, B., Zarka, P., and Cecconi, B.: Response of Jupiter's and Saturn's auroral activity to the solar wind, J. Geophys. Res.-Space, 114, A05210, https://doi.org/10.1029/2008ja013694, 2009.

Connerney, J. E. C., Adriani, A., Allegrini, F., Bagenal, F., Bolton, S. J., Bonfond, B., Cowley, S. W. H., Gérard, J. C., Gladstone, G. R., Grodent, D., Hospodarsky, G., Jorgensen, J. L., Kurth, W. S., Levin, S. M., Mauk, B., McComas, D. J., Mura, A., Paranicas, C., Smith, E. J., Thorne, R. M., Valek, P., and Waite, J.: Jupiter's magnetosphere and aurorae observed by the Juno spacecraft during its first polar orbits, Science, 356, 826-832, https://doi.org/10.1126/science.aam5928, 2017.

Cowley, S. W. H.: Asymmetry effects associated with the $\mathrm{x}$ component of the IMF in a magnetically open magnetosphere, Planet. Space Sci., 29, 809-818, https://doi.org/10.1016/00320633(81)90071-4, 1981.

Cowley, S. W. H. and Bunce, E. J.: Origin of the main auroral oval in Jupiter's coupled magnetosphere-ionosphere system, Planet. Space Sci., 49, 1067-1088, https://doi.org/10.1016/s00320633(00)00167-7, 2001.

Cowley, S. W. H. and Bunce, E. J.: Modulation of Jupiter's main auroral oval emissions by solar wind induced expansions and compressions of the magnetosphere, Planet. Space Sci., 51, 57-79, https://doi.org/10.1016/s0032-0633(02)00118-6, 2003a.

Cowley, S. W. H. and Bunce, E. J.: Corotation-driven magnetosphere-ionosphere coupling currents in Saturn's magnetosphere and their relation to the auroras, Ann. Geophys., 21, 1691-1707, https://doi.org/10.5194/angeo-21-1691-2003, 2003.

Cowley, S. W. H. and Hughes, W. J.: Observation of an IMF sector effect in the $Y$ magnetic field component at geostationary orbit, Planet. Space Sci., 31, 73-90, https://doi.org/10.1016/00320633(83)90032-6, 1983.

Cowley, S. W. H. and Lockwood, M.: Excitation and decay of solar wind-driven flows in the magnetosphere-ionosphere system, Ann. Geophys., 10, 103-115, 1992.

Cowley, S. W. H. and Lockwood, M.: Time-dependent flows in the coupled solar wind-magnetosphere-ionosphere system, Adv. Space Res., 18, 141-150, https://doi.org/10.1016/02731177(95)00972-8, 1996.

Cowley, S. W. H., Bunce, E. J., and Nichols, J. D.: Origins of Jupiter's main oval auroral emissions, J. Geophys. Res., 108, 8002, https://doi.org/10.1029/2002ja009329, 2003a.

Cowley, S. W. H., Bunce, E. J., Stallard, T. S., and Miller, S.: Jupiter's polar ionospheric flows: Theoretical interpretation, Geophys. Res. Lett., 30, 1220, https://doi.org/10.1029/2002gl016030, 2003b.
Cowley, S. W. H., Bunce, E. J., and Prangé, R.: Saturn's polar ionospheric flows and their relation to the main auroral oval, Ann. Geophys., 22, 1379-1394, https://doi.org/10.5194/angeo22-1379-2004, 2004a.

Cowley, S. W. H., Bunce, E. J., and O'Rourke, J. M.: A simple quantitative model of plasma flows and currents in Saturn's polar ionosphere, J. Geophys. Res., 109, A05212, https://doi.org/10.1029/2003ja010375, 2004b.

Cowley, S. W. H., Badman, S. V., Bunce, E. J., Clarke, J. T., Gérard, J. C., Grodent, D., Jackman, C. M., Milan, S. E., and Yeoman, T. K.: Reconnection in a rotation-dominated magnetosphere and its relation to Saturn's auroral dynamics, J. Geophys. Res., 110, https://doi.org/10.1029/2004ja010796, 2005.

Cowley, S. W. H., Arridge, C. S., Bunce, E. J., Clarke, J. T., Coates, A. J., Dougherty, M. K., Gérard, J.-C., Grodent, D., Nichols, J. D., and Talboys, D. L.: Auroral current systems in Saturn's magnetosphere: comparison of theoretical models with Cassini and HST observations, Ann. Geophys., 26, 2613-2630, https://doi.org/10.5194/angeo-26-2613-2008, 2008.

Cowley, S. W. H., Nichols, J. D., and Jackman, C. M.: Down-tail mass loss by plasmoids in Jupiter's and Saturn's magnetospheres, J. Geophys. Res.-Space, 120, 6347-6356, https://doi.org/10.1002/2015ja021500, 2015.

DiBraccio, G. A., Slavin, J. A., Boardsen, S. A., Anderson, B. J., Korth, H., Zurbuchen, T. H., Raines, J. M., Baker, D. N., McNutt, R. L., and Solomon, S. C.: MESSENGER observations of magnetopause structure and dynamics at Mercury, J. Geophys. Res.-Space, 118, 997-1008, https://doi.org/10.1002/jgra.50123, 2013.

Dungey, J. W.: Interplanetary Magnetic Field and the Auroral Zones, Phys. Rev. Lett., 6, 47-48, https://doi.org/10.1103/physrevlett.6.47, 1961.

Feldstein, Y. I.: The discovery and the first studies of the auroral oval: A review, Geomagn. Aeron.+, 56, 129-142, https://doi.org/10.1134/s0016793216020043, 2016.

Feldstein, Y. I., Vorobjev, V. G., Zverev, V. L., and Förster, M.: Investigations of the auroral luminosity distribution and the dynamics of discrete auroral forms in a historical retrospective, Hist. Geo Space. Sci., 5, 81-134, https://doi.org/10.5194/hgss-5-812014, 2014.

Gershman, D. J., Slavin, J. A., Raines, J. M., Zurbuchen, T. H., Anderson, B. J., Korth, H., Baker, D. N., and Solomon, S. C.: Magnetic flux pileup and plasma depletion in Mercury's subsolar magnetosheath, J. Geophys. Res.-Space, 118, 7181-7199, https://doi.org/10.1002/2013ja019244, 2013.

Grocott, A., Badman, S. V., Cowley, S. W. H., Milan, S. E., Nichols, J. D., and Yeoman, T. K.: Magnetosonic Mach number dependence of the efficiency of reconnection between planetary and interplanetary magnetic fields, J. Geophys. Res.-Space, 114, A07219, https://doi.org/10.1029/2009ja014330, 2009.

Grodent, D., Clarke, J. T., Waite, J. H., Cowley, S. W. H., Gérard, J. C., and Kim, J.: Jupiter's polar auroral emissions, J. Geophys. Res., 108, 1366, https://doi.org/10.1029/2003ja010017, 2003.

Hill, T. W.: The Jovian auroral oval, J. Geophys. Res.-Space, 106, 8101-8107, https://doi.org/10.1029/2000ja000302, 2001.

Huddleston, D. E., Russell, C. T., Le, G., and Szabo, A.: Magnetopause structure and the role of reconnection at the outer planets, J. Geophys. Res.-Space, 102, 24289-24302, https://doi.org/10.1029/97ja02416, 1997. 
Hultqvist, B.: On the importance of auroral processes in the Universe, J. Atmos. Sol.-Terr. Phy., 70, 2235-2245, https://doi.org/10.1016/j.jastp.2008.03.023, 2008.

Hunt, G. J., Cowley, S. W. G., Provan, G., Bunce, E. J., Alexeev, I. I., Belenkaya, E. S., Kalegaev, V. V., Dougherty, M. K., and Coates, A. J.: Field-aligned currents in Saturn's northern nightside magnetosphere: Evidence for interhemispheric current flow associated with planetary period oscillations, J. Geophys. Res.-Space, 120, 7552-7584, https://doi.org/10.1002/2015ja021454, 2015.

Jackman, C. M.: Saturn's magnetotail, in: Magnetotails in the Solar System, edited by: Keiling, A., Jackman, C. M., and Delamere, P. A., Geophysical Monograph, 99-118, AGU, Wiley, USA, 2015.

Jackman, C. M., Russell, C. T., Southwood, D. J., Arridge, C. S., Achilleos, N., and Dougherty, M. K.: Strong rapid dipolarizations in Saturn's magnetotail: In situ evidence of reconnection, Geophys. Res. Lett., 34, L11203, https://doi.org/10.1029/2007gl029764, 2007.

Jackman, C. M., Arridge, C. S., Krupp, N., Bunce, E. J., Mitchell, D. J., McAndrews, H. J., Dougherty, M. K., Russell, C. T., Achilleos, N., Jones, G. H., and Coates, A. J.: A multi-instrument view of tail reconnection at Saturn, J. Geophys. Res.-Space, 113, A11213, https://doi.org/10.1029/2008ja013592, 2008.

Jia, Y. D., Russell, L. K., Jian, C. T., Manchester, W. B., Cohen, O., Vourlidas, A., Hansen, K. C., Combi, M. R., and Gombosi, T. I.: Study of the 2007 april 20 CME-comet interaction event with an MHD model, Astrophys. J., 696, L56-L60, https://doi.org/10.1088/0004-637x/696/1/156, 2009.

Jinks, S. L., Bunce, E. J., Cowley, S. W. G., Provan, G., Yeoman, T. K., Arridge, C. S., Dougherty, M. K., Gurnett, D. A., Krupp, N., Kurth, W. S., Mitchell, D. G., Morooka, M., and Wahlund, J. E.: Cassini multi-instrument assessment of Saturn's polar cap boundary, J. Geophys. Res.-Space, 119, 8161-8177, https://doi.org/10.1002/2014ja020367, 2014.

Khurana, K. K., Kivelson, M. G., Vasyliunas, V. M., Krupp, N., Woch, J., Lagg, A., Mauk, W., and Kurth, W. S.: The configuration of Jupiter's magnetosphere, in: Jupiter. The planet, satellites and magnetosphere, edited by: Bagenal, F., Dowling, T., and McKinnon, W., Cambridge Planetary Science, 593-616, Cambridge University Press, Cambridge, UK, 2004.

Krupp, N., Vasyliunas, V. M., Woch, J., Lagg, A., Khurana, K. K., Kivelson, M. G., Mauk, B. H., Roelof, E. C., Williams, D. J., Krimigis, S. M., Kurth, W. S., Frank, L. A., and Paterson, W. R.: Dynamics of the Jovian magnetosphere, in: Jupiter. The planet, satellites and magnetosphere, edited by: Bagenal, F., Dowling, T., and McKinnon, W., Cambridge Planetary Science, 617-638, Cambridge University Press, Cambridge, UK, 2004.

Lai, H. R., Wei, H. Y., Russell, C. T., Arridge, C. S., and Dougherty, M. K.: Reconnection at the magnetopause of Saturn: Perspective from FTE occurrence and magnetosphere size, J. Geophys. Res.Space, 117, A05222, https://doi.org/10.1029/2011ja017263, 2012.

Masters, A., Phan, T. D., Badman, S. V., Hasegawa, H., Fujimoto, M., Russell, C. T., Coates, A. J., and Dougherty, M. K.: The plasma depletion layer in Saturn's magnetosheath, J. Geophys. Res.-Space, 119, 121-130, https://doi.org/10.1002/2013ja019516, 2014.

Mauk, B. and Bagenal, F.: Comparative Auroral Physics: Earth and Other Planets, in: Auroral Phenomenology and Magnetospheric
Processes: Earth And Other Planets, edited by: Keiling, A., Donovan, E., Bagenal, F., and Karlsson, T., American Geophysical Union, Geophysical Monograph Series 197, 3-26, Washington, D.C., https://doi.org/10.1029/2011GM001192, 2012.

McAndrews, H. J., Owen, C. J., Thomsen, M. F., Lavraud, B., Coates, A. J., Dougherty, M. K., and Young, D. T.: Evidence for reconnection at Saturn's magnetopause, J. Geophys. Res.-Space, 113, A04210, https://doi.org/10.1029/2007ja012581, 2008.

Meredith, C. J., Alexeev, I. I., Badman, S. V., Belenkaya, E. S., Cowley, S. W. H., Dougherty, M. K., Kalegaev, V. V., Lewis, G. R., and Nichols, J. D.: Saturn's dayside ultraviolet auroras: Evidence for morphological dependence on the direction of the upstream interplanetary magnetic field, J. Geophys. Res.-Space, 119, 1994-2008, https://doi.org/10.1002/2013ja019598, 2014.

Müller, A. L., Saur, J., Krupp, N., Roussos, E., Mauk, B. H., Rymer, A. M., Mitchell, D. G., and Krimigis, S. M.: Azimuthal plasma flow in the Kronian magnetosphere, J. Geophys. Res.-Space, 115, A08203, https://doi.org/10.1029/2009ja015122, 2010.

Øieroset, M., Mitchell, D. L., Phan, T. D., Lin, R. P., Crider, D. H., and Acuña, M. H.: The Magnetic Field Pile-up and Density Depletion in the Martian Magnetosheath: A Comparison with the Plasma Depletion Layer Upstream of the Earth's Magnetopause, Space Sci. Rev., 111, 185-202, https://doi.org/10.1023/b:spac.0000032715.69695.9c, 2004.

Pallier, L. and Prangé, R.: More about the structure of the high latitude Jovian aurorae, Planet. Space Sci., 49, 1159-1173, https://doi.org/10.1016/s0032-0633(01)00023-x, 2001.

Palmaerts, B., Radioti, A., Grodent, D., Gérard, J.-C., Krupp, N., and Mitchell, D. G.: Pulsations of the polar cusp aurora at Saturn, J. Geophys. Res.-Space, 121, 11952-11963, https://doi.org/10.1002/2016ja023497, 2016.

Phan, T.-D., Paschmann, G., Baumjohann, W., Sckopke, N., and Lühr, H.: The magnetosheath region adjacent to the dayside magnetopause: AMPTE/IRM observations, J. Geophys. Res., 99, 121-141, https://doi.org/10.1029/93ja02444, 1994.

Radioti, A. D., Grodent, D., Gérard, J. C., Milan, S. E., Bonfond, B., Gustin, J., and Pryor, W.: Bifurcations of the main auroral ring at Saturn: ionospheric signatures of consecutive reconnection events at the magnetopause, J. Geophys. Res.-Space, 116, A11209, https://doi.org/10.1029/2011ja016661, 2011.

Radioti, A. D., Grodent, D., Gérard, J. C., Bonfond, B., Gustin, J., Pryor, W., Jasinski, J. M., and Arridge, C. S.: Auroral signatures of multiple magnetopause reconnection at Saturn, Geophys. Res. Lett., 40, 4498-4502, https://doi.org/10.1002/grl.50889, 2013.

Richardson, J. D.: Thermal ions at Saturn: Plasma parameters and implications, J. Geophys. Res., 91, 1381, https://doi.org/10.1029/ja091ia02p01381, 1986.

Richardson, J. D. and Sittler Jr., E. C.: A plasma density model for Saturn based on Voyager observations, J. Geophys. Res., 95, 12019, https://doi.org/10.1029/ja095ia08p12019, 1990.

Saur, J., Pouquet, A., and Matthaeus, W. H.: An acceleration mechanism for the generation of the main auroral oval on Jupiter, Geophys. Res. Lett., 30, 1260, https://doi.org/10.1029/2002g1015761, 2003.

Scurry, L. and Russell, C. T.: Proxy studies of energy transfer to the magnetosphere, J. Geophys. Res., 96, 9541, https://doi.org/10.1029/91ja00569, 1991. 
Scurry, L., Russell, C. T., and Gosling, J. T.: Geomagnetic activity and the beta dependence of the dayside reconnection rate, J. Geophys. Res., 99, 14811, https://doi.org/10.1029/94ja00794, 1994.

Slavin, J. A., Acuña, M. H., Anderson, B. J., Baker, D. N., Benna, M., Boardsen, S. A., Gloeckler, G., Gold, R. E., Ho, G. C., Korth, H., and Krimigis, S. M.: MESSENGER Observations of Magnetic Reconnection in Mercury's Magnetosphere, Science, 324, 606-610, https://doi.org/10.1126/science.1172011, 2009.

Smith, A. W., Jackman, C. M., and Thomsen, M. F.: Magnetic reconnection in Saturn's magnetotail: A comprehensive magnetic field survey, J. Geophys. Res.-Space, 121, 2984-3005, https://doi.org/10.1002/2015ja022005, 2016.

Stallard, T. S., Miller, S., Melin, H., Trafton, L. M., Geballe, T. R., and Joseph, R. D.: Ion winds in Saturn's southern auroral/polar region, Icarus, 167, 204-211, https://doi.org/10.1016/j.icarus.2003.09.006, 2004.

Vignes, D., Mazelle, C., Reme, H., Acuña, M. H., Connerney, J. E. P., Lin, R. P., Mitchell, D. L., Cloutier, P., Crider, D. H., and Ness, N. F.: The solar wind interaction with Mars: Locations and shapes of the bow shock and the magnetic pile-up boundary from the observations of the MAG/ER Experiment onboard Mars Global Surveyor, Geophys. Res. Lett., 27, 49-52, https://doi.org/10.1029/1999gl010703, 2000.

Violante, L., Bavassano-Cattaneo, M. B., Moreno, G., and Richardson, J. D.: Observations of mirror waves and plasma depletion layer upstream of Saturn's magnetopause, J. Geophys. Res., 100, 12047, https://doi.org/10.1029/94ja02703, 1995.
Vogt, M. F., Kivelson, M. G., Khurana, K. K., Walker, R. J., Bonfond, B., Grodent, D., and Radioti, A.: Improved mapping of Jupiter's auroral features to magnetospheric sources, J. Geophys. Res.-Space, 116, A03220, https://doi.org/10.1029/2010ja016148, 2011.

Wilson, R. J., Bagenal, F., and Persoon, A. M.: Survey of thermal plasma ions in Saturn's magnetosphere utilizing a forward model, J. Geophys. Res.-Space, 122, 7256-7278, https://doi.org/10.1002/2017ja024117, 2017.

Zhang, T. L., Delva, M., Baumjohann, W., Volwerk, M., Russell, C. T., Barabash, S., Balikhin, M., Pope, S., Glassmeier, K. H., Wang, C., and Kudela, K.: Initial Venus Express magnetic field observations of the magnetic barrier at solar minimum, Planet. Space Sci., 56, 790-795, https://doi.org/10.1016/j.pss.2007.10.013, 2008.

Zhang, T. L., Lu, Q. M., Baumjohann, W., Russell, C. T., Fedorov, A., Barabash, S., Coates, A. J., Du, J. B., Cao, R., Nakamura, W. L., Teh, W. L., Wang, R. S., Dou, X. K., Wang, S., Glassmeier, K. H., Auster, H. U., and Balikhin, M.: Magnetic Reconnection in the Near Venusian Magnetotail, Science, 336, 567570, https://doi.org/10.1126/science.1217013, 2012. 